Working Paper 09-41

Economic Series (22)

June 2009
Departamento de Economía Universidad Carlos III de Madrid

Calle Madrid, 126

28903 Getafe (Spain)

Fax (34) 916249875

\title{
What Drives International Equity Correlations? Volatility or Market Direction?*
}

\author{
Khaled Amira ${ }^{\dagger}$ \\ Suffolk University, Boston \\ Georges Tsafack ${ }^{\S}$ \\ Suffolk University, Boston
}

Abderrahim Taamouti ${ }^{\ddagger}$

Universidad Carlos III de Madrid

June 26, 2009

\begin{abstract}
We consider impulse response functions to study the impact of both return and volatility on correlation between international equity markets. Using data on US (as the reference country), Canada, UK and France equity indices, empirical evidence shows that without taking into account the effect of return, there is an (asymmetric) effect of volatility on correlation. The volatility seems to have an impact on correlation especially during downturn periods. However, once we introduce the effect of return, the impact of volatility on correlation disappears. These observations suggest that, the relation between volatility and correlation is an association rather than a causality. The strong increase in the correlation is driven by the past of the return and the market direction rather than the volatility.
\end{abstract}

JEL Classification: C32, C51, G15.

Keywords: International equity markets, asymmetric volatility, asymmetric correlation, vector autoregressive (VAR), DCC-GARCH, Generalized impulse response function, Granger causality.

\footnotetext{
* This paper was previously circulating under the title "Asymmetric Effects of Return and Volatility on Correlation between International Equity Markets".

† Sawyer Business School, Department of Finance, 8 Ashburton Place, Boston, MA 02108; Tel: (617) 305 1799; Fax: 617.305.1755 Email: kamira@suffolk.edu

‡ Economics Department, Universidad Carlos III de Madrid. Adresse and e-mail: Departamento de Economía Universidad Carlos III de Madrid Calle Madrid, 12628903 Getafe (Madrid) España. Tel: +3491 6249863; Fax: +34-91 6249329; e-mail: ataamout@eco.uc3m.es.

$\S$ Correspondence Address: Sawyer Business School, Department of Finance, 8 Ashburton Place, Boston, MA 02108; Tel: (617) 994 4271; Fax: 617.3051755 Email: gtsafack@suffolk.edu
} 


\section{Introduction}

Recent research suggest an increase of correlation between international markets during volatile periods [see Ang and Bekaert (2002) and Ang and Chen (2002)]. This increase of correlation is especially observed during market downturns. Ang and Bekaert (2002) use a two-regime switching model and find evidence of one state with low returns and high correlation and volatilities, and a second state with high returns and low correlation and volatilities. Longin and Solnik (2001), use extreme value theory and develop a new concept named exceedance correlation, and find a high correlation between large negative returns and zero correlation between large positive returns. Ang and Chen (2002) provide some tests for the asymmetric correlation based on exceedance correlation. They apply these tests to a set of classical models and find that the best model to reproduce the asymmetric dependence is a two-regime switching model with a similar association between volatility and correlation. However, Forbes and Rigobon (2002) show that a volatility bias exists when analyzing the change into correlation in more volatile markets environment. After correcting for this bias, they find that there is no change in correlation (no contagion), but only interdependence between international financial markets.

Another well known stylized fact is the asymmetric relationship between volatility and return. Bad news (negative return shocks) has a larger effect on volatility compared to good news (positive return shocks) of the same magnitude. Two main explanations for this asymmetry have been proposed in the literature. The first one is the leverage effect [see Black (1976) and Christie (1982)] and the second one is the volatility feedback effect [see Pindyck (1984) and Campbell and Hentschel (1992), Bekaert and Wu (2000) among others]. ${ }^{1}$ Studies focusing on the leverage hypothesis conclude that it cannot completely account for changes in volatility; see Christie (1982) and Schwert (1989) while studies focusing on the volatility feedback effect have conflicting empirical findings. French, Schwert, and Stambaugh (1987), Campbell and Hentschel (1992), find a positive relation between volatility and expected returns, while Turner, Startz, and Nelson (1989), Glosten, Jagannathan, and Runkle (1993), and Nelson (1991) find the relation to be negative. Often the coefficient linking volatility to returns is statistically insignificant. Bollerslev, Litvinova, and Tauchen (2006) further explore these relationships using high frequency data and realized volatility measures. They find a significant negative correlation between volatility and current and lagged returns lasting for

\footnotetext{
${ }^{1}$ The leverage hypothesis asserts that return shocks lead to changes in conditional volatility, while the volatility feedback effect theory assumes that return shocks can be caused by changes in conditional volatility through a time-varying risk premium.
} 
several days, and a close to zero correlation between returns and lagged volatility. ${ }^{2}$

The above discussions raise some important questions that our study will address: Is there any causal effect of volatility on correlation in the international equity markets? If such causality exists, then what is the relative behavior of this effect during bad and good times? Knowing that an asymmetric GARCH effect exists between equity return and volatility, what will happen when we consider the effect of volatility along with the effect of returns on correlation? What is the economic gain of taking into account this effect while optimizing the portfolio?

In this paper, we study the impact of news (innovations in returns) and volatility on correlation between international equity market returns. ${ }^{3}$ We are especially interested in exploring their asymmetric effect on correlation and identifying the main driver of this asymmetry in correlation. Within the framework of a vector autoregressive (VAR) model, we quantify the relationships between volatility and correlation, using the generalized impulse response functions. In a similar framework we introduce the asymmetry by separating volatility in a time of a market upturn from volatility in a time of a market downturn. We conduct the same analysis to investigate the asymmetric effect of news on correlation. Finally, we simultaneously analyze the asymmetric effects of returns and volatility on correlation to better understand what the actual source of the asymmetry in correlation between international equity markets is. We examine the gain of taking into account the asymmetric effect of return on correlation for the optimal international diversification.

Our empirical investigation is performed using weekly data on US (as the reference country), Canada, UK, and France equity returns. The results show that the effect of news on the correlation between international equity market returns is asymmetric. Negative innovations in returns increase the correlation more than positive innovations with the same magnitude. For short and intermediate horizons and in the absence of news, the correlation between international equity market returns is asymmetric with respect to volatility during downturn and upturn markets. However, in the presence of news this correlation is symmetric (or has no effect) with respect to volatility: The volatility implied by a decrease in equity prices has the same (little) impact on correlation as the volatility implied by an increase in equity prices. This observation suggests that in the presence of return the asymmetry in the volatility-correlation relationship is absorbed by the asymmetric relationship between returns and correlation. The increase in the correlation is driven by the market

\footnotetext{
${ }^{2}$ For more details about the asymmetric volatility phenomena, see Dufour, Garcia, and Taamouti (2008).

${ }^{3}$ In a related work Cappiello, Engle, and Sheppard (2006) introduce asymmetry in the DCC. They characterize the effect of a joint bad (good) news on correlation. Applying their model to global equity and bond return, they find an increase in correlation between European countries after the introduction of the Euro currency period.
} 
direction rather than the level of volatility. These results are confirmed after using some separate and joint tests of the asymmetry in return-correlation and volatility-correlation relationships. The association and Granger causality tests show that volatility does not cause correlation, while return strongly cause correlation. Finally, we show that taking into account the asymmetric effect of return on correlation leads to a financial gain in terms of the optimal international diversification. This gain ranges between 2.15 and 27.50 basis points (bps).

The remainder of this paper is organized as follows. In Section 2, we present a number of alternative approaches used for the estimation of volatilities and correlations. Section 3 provides a framework to analyze the impact of volatility on correlation. Section 4 we introduce the asymmetric effects of both return and volatility on correlation. We specify the models that we use to test these asymmetric effects in Section 5, and examine the implication of the asymmetric effects on the optimal international portfolio in Section 6. Section, 7 presents the empirical results and Section 8 concludes.

\section{Estimation of volatilities and correlations}

As the conditional volatilities and correlations cannot be observed they need to be estimated. We perform the estimation using both parametric and nonparametrical models.

\subsection{Parametric estimation}

The parametric models that we use to estimate the conditional volatilities and correlations are decomposed into two different related parts. In the first one we use the Generalized autoregressive conditional heteroskedasticity model (hereafter GARCH model) and an asymmetric version (EGARCH) to filter the conditional volatility process from the specification of the conditional marginal distribution. In the second part we use the Dynamic conditional correlation model (hereafter DCC model) and the filtered volatilities to estimate the conditional correlation process.

\subsubsection{GARCH and EGARCH filters}

A common approach to filter volatilities is to use the GARCH model introduced by Bollerslev (1986). In our study, we consider two different types of GARCH specifications. The first one is a symmetric GARCH model that we use as a benchmark in our framework. In this model the impact of positive and negative news is supposed to be symmetric. The second type of GARCH specification (hereafter EGARCH) developed by Nelson (1991) stipulates that negative and positive 
returns have different impact on volatility.

For each of the above GARCH specifications, we assume that the returns on indices for all countries are given by the following model:

$$
r_{i, t+1}=\mu_{i}+\varepsilon_{i, t+1}, \quad \text { with } \varepsilon_{i, t+1}=\sigma_{i, t+1} z_{i, t+1} \text {, and } z_{i, t+1} i . i . d . \sim \mathcal{N}(0,1) .
$$

where $r_{i, t+1}=p_{i, t+1}-p_{i, t}$ is the continuously compounded returns from time $t$ to $t+1 . p_{i, t}$ is the time- $t$ logarithmic price index in the country $i$ in the empirical application $i=\mathrm{US}$, Canada, UK, France. In a first setup we assume that the volatility of returns $r_{i, t+1}$, say $\sigma_{i, t+1}$, is given by the following $\operatorname{GARCH}(1,1)$ model:

$$
\sigma_{i, t+1}^{2}=\omega_{i}+\beta_{i} \sigma_{i, t}^{2}+\alpha_{i} \varepsilon_{i, t}^{2}
$$

and in a second setup we suppose that the volatility $\sigma_{i, t+1}$ is given by the following Nelson (1991) EGARCH $(1,1)$ model that can be rewritten in a more simple and intuitive way as follows:

$$
\ln \left(\sigma_{i, t+1}\right)=\omega_{i}+\beta_{i} \ln \left(\sigma_{i, t}\right)+\alpha_{i}\left(\left|z_{i, t}\right|-c z_{i, t}\right)
$$

Parameter $c$ in (3) allows to capture the well known asymmetric volatility phenomena, where negative returns have a higher effect on volatility compared to positive returns of same magnitude.

In the next section, we use the dynamic conditional correlation model of Engle (2002) to filter the correlation process.

\subsubsection{Dynamic conditional correlation (DCC)}

Recently proposed by Engle (2002) to capture the time dynamics in the correlation, the DCC model is becoming a benchmark model for multivariate specifications. One of the attractive properties

of this model is its flexibility in term of specification of marginal distributions separately from the dependence structure. For a bivariate process, the $\operatorname{GARCH}(1,1)$-type specification of conditional correlation coefficient, say $\rho_{i, t}$, is given by:

$$
\rho_{i, t}=\operatorname{Corr}\left(r_{U S, t}, r_{i, t}\right)=\frac{q_{U S i, t}}{\sqrt{q_{U S U S, t} q_{i i, t}}}
$$

where the auxiliary variable $q_{i j, t}$ is defined by the dynamic

$$
q_{i j, t}=\bar{\rho}_{i j}+a_{i}\left(z_{i, t-1} z_{j, t-1}-\bar{\rho}_{i j}\right)+b_{i}\left(q_{i j, t-1}-\bar{\rho}_{i j}\right)
$$

$\bar{\rho}_{i j}$ is the unconditional expectation of the cross-product of return innovations between country $i$ and $j$ for $i \neq j$, and is equal to 1 for $i=j$. 


\subsection{Nonparametric estimation}

We also consider a nonparametric estimation of volatilities and correlations. Our motivation for using a nonparametric approach is to get a model-free estimation for these quantities and avoid the impact that parametric models may have on the empirical results and further allows us to check the robutsness of our results.

To estimate nonparametrically volatilities and correlations between different international financial markets, we use an arithmetic equally weighted estimator (hereafter moving average estimator). For a sample of historical observations on returns for the four financial markets $\left\{r_{i, t}\right\}_{t=1}^{T},(i=\mathrm{US}$, Canada, UK, and France), the moving average estimators of volatilities sqaured, say $\sigma_{i, t+1}^{2}$ and correlations between stock market returns in US and country $i$, say $\rho_{i, t+1}$, are given by the following formulas:

$$
\begin{aligned}
& \sigma_{i, t+1}^{2}=\frac{1}{m} \sum_{\tau=t-m}^{t}\left(r_{i, \tau}-\bar{r}_{i, t+1}\right)^{2} \\
& \rho_{i, t+1}=\frac{\sum_{\tau=t-m}^{t}\left(r_{U S, \tau}-\bar{r}_{U S, t+1}\right)\left(r_{i, \tau}-\bar{r}_{i, t+1}\right)}{\sqrt{\left(\sum_{\tau=t-m}^{t}\left(r_{i, \tau}-\bar{r}_{i, t+1}\right)^{2}\right)\left(\sum_{\tau=t-m}^{t}\left(r_{U S, \tau}-\bar{r}_{U S, t+1}\right)^{2}\right)}}, \text { for } \quad i \neq U S
\end{aligned}
$$

where $r_{U S, \tau}$ is the US equity market return and

$$
\bar{r}_{i, t+1}=\frac{1}{m} \sum_{\tau=t-m}^{t} r_{i, \tau} .
$$

In the empirical application we consider different values for the window $m$ (30, 50, and 70 weeks).

\section{Impact of volatility on correlation}

In this section, we study the impact of volatility on the correlation between international equity markets. The objective is to measure the effect of changes in the US (reference market) volatility on the correlation between US and the foreign equity market returns. This effect is quantified within the context of a vector autoregressive (VAR) model and by using the generalized impulse response functions.

We assume that the joint process of the logarithmic of the US volatility squared, $\operatorname{say} \ln \left(\sigma_{U S, t+1}^{2}\right)$, logarithmic foreign (country $i$ ) volatility squared, say $\ln \left(\sigma_{i, t+1}^{2}\right)$, and reverse logistic transformation of correlation between US and foreign equity returns, say $l\left(\rho_{i, t+1}\right)$, follows an autoregressive linear $\operatorname{model}^{4}$

\footnotetext{
${ }^{4}$ We perform the analysis for different values of the order of autoregressive model, and find that the VAR(1) is a more parsimonious model.
} 


$$
\left(\begin{array}{c}
l\left(\rho_{i, t+1}\right) \\
\ln \left(\sigma_{U S, t+1}^{2}\right) \\
\ln \left(\sigma_{i, t+1}^{2}\right)
\end{array}\right)=\left(\begin{array}{c}
\mu_{\rho_{i}} \\
\mu_{\sigma_{U S}} \\
\mu_{\sigma_{i}}
\end{array}\right)+\left[\begin{array}{lll}
\Phi_{11} & \Phi_{12} & \Phi_{13} \\
\Phi_{21} & \Phi_{22} & \Phi_{23} \\
\Phi_{31} & \Phi_{32} & \Phi_{33}
\end{array}\right]\left(\begin{array}{c}
l\left(\rho_{i, t}\right) \\
\ln \left(\sigma_{U S, t}^{2}\right) \\
\ln \left(\sigma_{i, t}^{2}\right)
\end{array}\right)+\underbrace{\left(\begin{array}{c}
u_{t+1}^{\rho_{i}} \\
u_{t+1}^{\sigma} \\
u_{t+1}^{\sigma \sigma_{i}}
\end{array}\right)}_{u_{t+1}}
$$

where

$$
E\left[u_{t}\right]=0, \text { and } E\left[u_{s} u_{t}^{\prime}\right]=\left\{\begin{array}{ll}
\Sigma_{u} & \text { for } s=t \\
0 & \text { for } s \neq t
\end{array} .\right.
$$

The variable $l\left(\rho_{i, t+1}\right)$ represents a reverse logistic transformation of correlation $\rho_{i, t+1}$ :

$$
l\left(\rho_{i, t+1}\right)=\ln \left(\frac{1+\rho_{i, t+1}}{1-\rho_{i, t+1}}\right) .
$$

Observe that, if $\rho_{i, t+1} \in(-1,1)$ then

$$
\ln \left(\frac{1+\rho_{i, t+1}}{1-\rho_{i, t+1}}\right) \in(-\infty,+\infty)
$$

The transformed variable $l\left(\rho_{i, t+1}\right)$ can take any value on the real line, which is consistent with the assumption made on the error term $u_{t+1}$. In the empirical application, $\sigma_{U S, t+1}^{2}$ and $\sigma_{i, t+1}^{2}$ will be replaced by the volatilities estimated using the parametric (GARCH, EGARCH) models or using nonparametric approach of Section (2.2). The disturbance $u_{t+1}^{\rho_{i}}$ is the one-step-ahead error when $l\left(\rho_{i, t+1}\right)$ is forecasted from its own past and the past of variables $\ln \left(\sigma_{U S, t+1}^{2}\right)$ and $\ln \left(\sigma_{i, t+1}^{2}\right)$. Similarly $u_{t+1}^{\sigma_{U S}}\left(u_{t+1}^{\sigma_{i}}\right)$ represents the one-step-ahead error when $\ln \left(\sigma_{U S, t+1}^{2}\right)\left(\right.$ resp. $\left.\ln \left(\sigma_{i, t+1}^{2}\right)\right)$ is forecasted from its own past and the past of $l\left(\rho_{i, t+1}\right)$ and $\ln \left(\sigma_{i, t+1}^{2}\right)$ (resp. $\left.\ln \left(\sigma_{U S, t+1}^{2}\right)\right)$. We assume that these disturbances are each serially uncorrelated, but may be correlated with each other contemporaneously and at various leads and lags. Since $u_{t+1}^{\rho_{i}}$ is uncorrelated with the past of correlations and volatilities, hereafter $I_{t}$, the equation for $l\left(\rho_{i, t+1}\right)$ represents the linear projection of $l\left(\rho_{i, t+1}\right)$ on $I_{t}$. Likewise, the equation for $\ln \left(\sigma_{U S, t+1}^{2}\right)$ (resp. $\left.\ln \left(\sigma_{i, t+1}^{2}\right)\right)$ represents the linear projection of $\ln \left(\sigma_{U S, t+1}^{2}\right)$ (resp. $\left.\ln \left(\sigma_{i, t+1}^{2}\right)\right)$ on $I_{t}$.

Equation (6) allows to model the conditional volatilities and correlation between equity returns. We model conditional volatility as an exponential function to guarantee its positivity and we transform the correlation as in (8) to avoid the restriction $-1 \leq \rho_{i} \leq+1 .^{5}$ The first equation of $V A R(p)$ in (6) describes the dynamics of the correlation as

$$
l\left(\rho_{i, t+1}\right)=\mu_{\rho_{i}}+\Phi_{11} l\left(\rho_{i, t}\right)+\Phi_{12} \ln \left(\sigma_{U S, t}^{2}\right)+\Phi_{13} \ln \left(\sigma_{i, t}^{2}\right)+u_{t+1}^{\rho_{i}} .
$$

This equation represents a stochastic model for correlation between US and foreign equity returns. This correlation is a function of its own past, the past of US and foreign volatilities, and an error

\footnotetext{
${ }^{5}$ In the empirical application, when we also consider linear regressions using volatilities and correlations in levels the results do not change.
} 
term $u_{t+1}^{\rho_{i}}$. The impact of US volatility on the correlation is captured by the coefficient $\Phi_{12}$. Further, the coefficient $\Phi_{13}$ captures the impact of foreign volatility on the correlation. The second and third equations of the above $V A R(1)$ model describe the dynamics of the US and foreign volatilities. These equations are a function of their own past, the past of correlation, and an error term.

\section{Asymmetric effects on correlation}

One of the many stylized facts about equity returns is the existence of an asymmetric relationship between returns and volatility. Volatility tends to rise following negative returns and to fall following positive returns [see Black (1976), Christie (1982), Engle and Ng (1993) among others]. Using autoregressive models and parametric and nonparametric estimates of volatilities and correlations, we perform a similar investigation to examine the nature (symmetric or asymmetric) of the effect of news (positive and negative returns) and volatility (upturn and downturn volatilities) on the correlation between international equity markets.

\subsection{Impact of upturn and downturn volatilities on correlation}

We study the asymmetry in the correlation between the US and foreign (Canada, UK, and France) equity markets. We decompose volatility into upturn and downturn volatilities and examine their impact on correlation. The upturn (downturn) volatility corresponds to a volatility associated with an increase (decrease) in the US equity prices.

We extend our previous VAR model to capture the dynamic effects of upturn and downturn volatilities on correlation. The model that we consider is defined by the following regression equation:

$$
l\left(\rho_{i, t+1}\right)=\delta_{\rho_{i}}+\phi_{i} l\left(\rho_{i, t}\right)+\phi_{i}^{-} \cdot \mathbb{I}_{t}^{-} \cdot \ln \left(\sigma_{U S, t}^{2}\right)+\phi_{i}^{+} \cdot \mathbb{I}_{t}^{+} \cdot \ln \left(\sigma_{U S, t}^{2}\right)+v_{t+1}^{i},
$$

where

$$
\mathbb{I}_{t}^{+}=\left\{\begin{array}{l}
1 \text { if } r_{U S, t} \geq 0 \\
0, \text { otherwise }
\end{array}, \quad \mathbb{I}_{t}^{-}=1-\mathbb{I}_{t}^{+},\right.
$$

$r_{U S, t+1}$ is the US equity market return and $v_{t+1}^{i}$ is an error term which follows similar assumptions as in (7). Equation (9) represents the linear regression of correlation on its own past and the past of US upturn and downturn volatilities. This regression model allows to capture the effects of upturn and downturn volatilities on correlation through the coefficients $\phi_{i}^{-}$and $\phi_{i}^{+}$, respectively. One way 
to compare the strength of these effects is to compute their generalized impulse response functions [see Section 7].

\subsection{Impact of return news on correlation}

We study the impact of bad news (negative innovations in returns) and good news (positive innovations in returns) on the correlation between international equity markets. We quantify and compare the strength of these impacts using the generalized impulse response functions. To examine the impact of news on correlation, we consider the following model:

$$
l\left(\rho_{i, t+1}\right)=\eta_{\rho_{i}}+\varphi_{i} l\left(\rho_{i, t}\right)+\varphi_{i}^{-} \cdot \min \left\{\operatorname{Re}_{U S, t}, 0\right\}+\varphi_{i}^{+} \cdot \max \left\{\operatorname{Re}_{U S, t+1-j}, 0\right\}+\varepsilon_{t+1}^{i},
$$

where the news in the US equity market is difined by:

$$
\operatorname{Re}_{U S, t}=r_{U S, t}-E_{t-1}\left(r_{U S, t}\right)
$$

and $\varepsilon_{t+1}^{i}$ is an error term which follows similar assumptions as in (7). In our empirical application, the conditional mean $E_{t}\left(r_{U S, t+1}\right)$ is approximated by the following rolling-sample average:

$$
\hat{E}_{t}\left(r_{U S, t+1}\right)=\frac{1}{m} \sum_{j=1}^{m} r_{t+1-j}
$$

where we take an average around $m=30,50$, or 70 weeks. Equation (11) represents the linear regression of correlation on its own past and the past of centered negative and positive returns. This regression model allows to capture the effect of centered negative and positive returns on correlation through the coefficients $\varphi_{i}^{-}$and $\varphi_{i}^{+}$, respectively. A negative (positive) sign for $\varphi_{i}^{-}\left(\varphi_{i}^{+}\right)$ means that an increase in the absolute value of a negative (positive) return has a positive effect on the future correlation $\left(\rho_{i, t+1}\right)$. It also allows to examine the impacts of large and small negative and/or positive information shocks on the correlation. In the empirical application we also consider a model with non centered negative and positive returns:

$$
l\left(\rho_{i, t+1}\right)=\omega_{\rho_{i}}+\delta_{i} l\left(\rho_{i, t}\right)+\delta_{i}^{-} \cdot \min \left\{r_{U S, t}, 0\right\}+\delta_{i}^{+} \cdot \max \left\{r_{U S, t}, 0\right\}+\nu_{t+1}^{i},
$$

where $\nu_{t+1}^{i}$ is an error term which follows similar assumptions as in (7). This regression model allows to capture the effect of non centered negative and positive returns on correlation through the coefficients $\delta_{i}^{-}$and $\delta_{i}^{+}$, respectively. Using this regression model allows to avoid the impact that the estimator of conditional mean (12) can have on the empirical results. 


\section{$5 \quad$ Testing for asymmetric effects}

One of the main objectives of this study is to test for the asymmetries in the volatility-correlation and returns-correlation relationships and examine the possible interactions between them. More specifically, knowing that an asymmetric effect exists between equity returns and volatility, what will happen when we consider the effect of volatility along with the effect of returns on correlation?

To test for the asymmetry, at different horizons, of the impact of returns and volatility on correlation, we use different regression models. First, to test the asymmetric effect of volatility on correlation in the absence of return we consider the following regression model

$$
l\left(\rho_{i, t+h}\right)=\varpi_{h}^{i}+\psi_{h}^{i} l\left(\rho_{i, t}\right)+\zeta_{h}^{i-} \cdot \mathbb{I}_{t}^{-} \ln \left(\sigma_{U S, t}^{2}\right)+\bar{\zeta}_{h}^{i} \ln \left(\sigma_{U S, t}^{2}\right)+v_{t+h}^{i}, \text { for } h \geq 1,
$$

where $\mathbb{I}_{t}^{-}$is defined in (10). The null and the alternative hypotheses are given by:

$$
\left\{\begin{array}{l}
H_{0}: \zeta_{h}^{i-}=0 \\
H_{1}: \zeta_{h}^{i-} \neq 0 \quad\left(\text { or } \quad H_{1}^{\prime}: \zeta_{h}^{i-}>0\right)
\end{array} .\right.
$$

Now, to test for the asymmetric relationship between return and correlation in the absence of volatility we consider the model

$$
l\left(\rho_{i, t+h}\right)=\lambda_{h}^{i}+\xi_{h}^{i} l\left(\rho_{i, t}\right)+\varphi_{h}^{i-} \cdot I_{t}^{-}\left|\operatorname{Re}_{U S, t}\right|+\bar{\varphi}_{h}^{i} \operatorname{Re}_{U S, t}+e_{t+h}^{i}, \text { for } h \geq 1
$$

and the null and the alternative hypotheses

$$
\left\{\begin{array}{l}
H_{0}: \varphi_{h}^{i-}=0 \\
H_{1}: \varphi_{h}^{i-} \neq 0 \quad\left(\text { or } \quad H_{1}^{\prime}: \varphi_{h}^{i-}>0\right)
\end{array} .\right.
$$

It is worth noticing that since we use the absolute value of the return $\left|\operatorname{Re}_{U S, t}\right|$ a positive sign of $\varphi_{h}^{i-}$ means that negative return increases the correlation compare to a positive return of the same magnitude. Finally, we also consider a model which allows for the joint asymmetric effects of volatility and return

$$
l\left(\rho_{i, t+h}\right)=\eta_{h}^{i}+\varphi_{h}^{i} l\left(\rho_{i, t}\right)+\phi_{h}^{i-} \cdot \mathbb{I}_{t}^{-} \ln \left(\sigma_{U S, t}^{2}\right)+\bar{\phi}_{h}^{i} \ln \left(\sigma_{U S, t}^{2}\right)+\varphi_{h}^{i-} \cdot \mathbb{I}_{t}^{-}\left|\operatorname{Re}_{U S, t}\right|+\bar{\varphi}_{h}^{i} \operatorname{Re}_{U S, t}+\varepsilon_{t+h}^{i} .
$$

To test for the asymmetry in the volatility-correlation relationship at different horizons using the model (18), we consider the following hypotheses

$$
\left\{\begin{array}{l}
H_{0}: \phi_{h}^{i-}=0 \\
H_{1}: \phi_{h}^{i-} \neq 0, \quad\left(\text { or } \quad H_{1}^{\prime}: \phi_{h}^{i-}>0\right)
\end{array} \quad \text { for } h \geq 1\right.
$$


and to test for the asymmetry in the return-correlation relationship at different horizons using the same model, we consider the following hypotheses

$$
\left\{\begin{array}{l}
H_{0}: \varphi_{h}^{i-}=0 \\
H_{1}: \varphi_{h}^{i-} \neq 0, \quad\left(\text { or } \quad H_{1}^{\prime}: \varphi_{h}^{i-}>0\right)
\end{array} \quad \text { for } h \geq 1 .\right.
$$

Notice that, an estimator for variance-covariance matrix of the estimated parameters should take into account the fact that the prediction errors $v_{t+h}^{i}, e_{t+h}^{i}$, and $\varepsilon_{t+h}^{i}$ follow moving average $M A(h-1)$ processes of order $h-1$. To accurately estimate the standard errors of parameters, we need an estimator which takes into account the autocorrelation. The commonly used estimator is the one suggested by Newey and West (1987) [see also Doan and Litterman (1983) and Gallant (1987)]:

$$
\hat{V}(T)=\Gamma^{(h)}(0)+\sum_{\tau=1}^{w(T)-1} \kappa(\tau, w(T))\left[\Gamma^{(h)}(\tau)+\Gamma^{(h)}(\tau)^{\prime}\right],
$$

where $\kappa(\tau, w(T))=1-\left[\frac{\tau}{(w+1)}\right]$,

$$
\begin{gathered}
\Gamma^{(h)}(\tau)=\frac{1}{T-h} \sum_{t=\tau}^{T-h} Q^{(h)}(t+h) Q^{(h)}(t+h-\tau)^{\prime}, \tau=0,1,2, \ldots \\
Q^{(h)}(t+h)=X(t) w_{t+h}^{i},
\end{gathered}
$$

with $X(t)$ being the vector of independent variables and $w_{t+h}^{i}$ the residual. To test for the asymmetries discussed above, we use t-statistics based on the Newey-West estimator of the variancecovariance matrix [see Dufour, Pelletier, and Renault (2005)]. The choice of the bandwidth $w(T)$ depends on the autocorrelation function. For each horizon, we choose the appropriate bandwidth.

\section{Asymmetric effects and the international diversification}

We examine the economic implications of the asymmetric relations between returns and correlation on the optimal international diversification. We assume that international investors are risk averse with preferences defined over the conditional expectation and variance-covariance matrix of the equity returns.

\subsection{The investor problem}

To find the optimal conditional weight invested in the US equity, we consider the mean-variance behavior, characterized by an optimization problem in which the efficient frontier can be described as the set of portfolios that satisfy a constrained maximization problem. The international investor 
with an initial wealth of $W_{t}$ diversifies his portfolio between the US and the foreign equity indices according to the following problem

$$
\underset{w_{u s, t} \in \mathbb{R}}{\operatorname{Max}}\left\{W_{t} \mu\left(R_{p}\left(w_{u s, t}\right)\right)-\frac{\eta}{2} W_{t}^{2} \sigma^{2}\left(R_{p}\left(w_{u s, t}\right)\right)\right\},
$$

where $R_{p}\left(w_{u s, t}\right)$ is the return with $w_{u s, t}$ invested in US, $\mu\left(R_{p}\left(w_{u s, t}\right)\right)=w_{u s, t} \mu_{u s, t}+\left(1-w_{u s, t}\right) \mu_{i, t}$ is the mean return, and $\sigma^{2}\left(R_{p}\left(w_{u s, t}\right)\right)=w_{u s, t}^{2} \sigma_{u s, t}^{2}+\left(1-w_{u s, t}\right)^{2} \sigma_{i, t}^{2}+2 w_{u s, t}\left(1-w_{u s, t}\right) \rho_{i, t} \sigma_{u s, t} \sigma_{i, t}$ is the variance of the portfolio including the US equity and the equity of a country $i=$ Canada, UK, and France. The "multiplier" $\eta$ can be interpreted as a "risk aversion" coefficient. The solution to the problem (20) is given by the optimal share of US equity:

$$
w_{u s, t}^{*}=\frac{\left(\mu_{u s, t}-\mu_{i, t}\right)+\eta W_{t}\left(\sigma_{i, t}^{2}-\rho_{i, t} \sigma_{u s, t} \sigma_{i, t}\right)}{\eta W_{t}\left(\sigma_{u s, t}^{2}+\sigma_{i, t}^{2}-2 \rho_{i, t} \sigma_{u s, t} \sigma_{i, t}\right)} .
$$

\subsection{Financial gain of using the asymmetric effect of return on correlation}

We study the financial gain of using the asymmetric effect of return on correlation. Our analysis is based on the following expected utility function of the investor

$$
E U\left(R_{p}\left(w_{u s, t}\right)\right)=\mu\left(R_{p}\left(w_{u s, t}\right)\right)-\frac{\eta}{2} \sigma^{2}\left(R_{p}\left(w_{u s, t}\right)\right) .
$$

The initial wealth here is normalized to the unity, which can be interpreted as investing one dollar at the beginning of the period. We define the gain $g_{t}$ as the additional fraction of wealth necessary to an investor who is not aware of the asymmetry to match the same level of the utility of an investor who is aware of this asymetry. $\underline{w}_{u s, t}^{*}$ is the optimal share invested in the US market when the investor is not aware of the asymmetry, while $w_{u s, t}^{*}$ is the optimal share when the investor takes into account the asymmetry. To get a simple analytical solution to our problem, we assume that this fraction of wealth $g_{t}$ is not invested therefore it is the solution of the equation ${ }^{6}$

$$
E U\left(R_{p}\left(\underline{w}_{u s, t}^{*}\right)+g_{t}\right)=E U\left(R_{p}\left(w_{u s, t}^{*}\right)\right)
$$

and since $g_{t}$ is not random, the mean-variance utility function implies that

$$
g_{t}=E U\left(R_{p}\left(w_{u s, t}^{*}\right)\right)-E U\left(R_{p}\left(\underline{w}_{u s, t}^{*}\right)\right)
$$

with

$$
\underline{w}_{u s, t}^{*}=\frac{\left(\mu_{u s, t}-\mu_{i, t}\right)+\eta\left(\sigma_{i, t}^{2}-\underline{\rho}_{i, t} \sigma_{u s, t} \sigma_{i, t}\right)}{\eta\left(\sigma_{u s, t}^{2}+\sigma_{i, t}^{2}-2 \underline{\rho}_{i, t} \sigma_{u s, t} \sigma_{i, t}\right)}
$$

\footnotetext{
${ }^{6}$ If instead we assume that this fraction $g_{t}$ is invested, we will end up with a second order problem where the solution will depend on the values of coefficients. An in some circumstances, the solution does not exist.
} 
where $\underline{\rho}_{i, t}$ is the correlation coefficient forecasted without taking into account the asymmetry effect of return.

The average gain is presented in Tables 10. This table reports different values of risk aversion $(\eta=3,5$, and 7$)$ and different values of the window used to estimate moving average correlation. We choose these values based on the empirical findings in the literature [see for example French and Poterba (1991)].

To estimate the mean expected utility and gain functions we proceed as follows. First, we compute the correlation series between the US and the foreign country returns using the nonparametric approach described in Section (2.2). Second, we estimate the regression models

$$
l\left(\rho_{i, t}\right)=\lambda^{i}+\xi^{i} l\left(\rho_{i, t-1}\right)+\theta^{i-} \cdot \mathbb{I}_{t-1}^{-} \operatorname{Re}_{U S, t-1}+\theta^{i} \operatorname{Re}_{U S, t-1}+e_{t}^{i}
$$

and

$$
l\left(\rho_{i, t}\right)=\lambda^{i}+\xi^{i} l\left(\rho_{i, t-1}\right)+\theta^{i} \operatorname{Re}_{U S, t-1}+e_{t}^{i}
$$

which correspond to models of correlation with and without taking into account the asymmetric effect of return on correlation, respectively. Thereafter, we first recuperate the corresponding fittedvalues that we use to estimate the weights $w_{u s, t}^{*}$ and $\underline{w}_{u s, t}^{*}$, and then we compute the mean of the expected utility functions $E U\left(R_{p}\left(w_{u s, t}^{*}\right)\right), E U\left(R_{p}\left(\underline{w}_{u s, t}^{*}\right)\right)$ and of the gain $g_{t}$. To focus on the effect of asymmetry in the correlation, we use the unconditional estimates of the mean return and volatilities.

\section{Empirical evidence}

We examine the empirical evidence of a possible asymmetric relationship between volatility and correlation and return and correlation. We also analyze the interaction between both asymmetries and test for the statistical significance of the asymmetric effect of volatility on correlation in the presence and absence of asymmetric effect of return on correlation.

\subsection{Data and parameter estimates}

Our data consists of weekly observations on MSCI Equity Indices series for the US, Canada, UK, and France. The sample runs from October 16th 1984 to December 21th 2004 for a total of 1054 observations. The returns are computed using the standard continuous compounding formula. All returns are derived on a weekly basis from daily prices expressed in US dollars. Summary statistics for the US, Canada, UK, and France equity returns are presented in Table 1. These weekly returns 
are displayed in Figure 1. The unconditional distributions of the US, Canada, UK, and France equity weekly returns show the expected excess kurtosis and negative skewness [see Table 1]. The sample kurtosis is greater than the normal distribution value of three. The values of Jarque-Bera test statistic show that these equity returns are not normally distributed. The time series plots of returns show the familiar volatility clustering effect, along with some occasional large absolute returns [see Figure 1].

We use GARCH and EGARCH models to filter the US, Canada, UK, and France equity returns volatilities, and the DCC model to estimate the correlation between domistic (US) and other countries equity returns. The estimation results for GARCH and EGARCH models are presented in tables 2 and 3 and displayed in figures 2 and 4 . For all countries, the coefficients of the estimated GARCH models are statistically significant. The high values of the estimators of $\beta$ indicate that volatilities are persistent. The estimated coefficients of the EGARCH models are also statistically significant, except for the UK the coefficient of leverage effect, say $c$, is not significant. For the other countries, the estimates of the coefficients of leverage effect are statistically significant and negative. The latter means that there is an asymmetric relationship between volatility and return shocks: volatility tends to rise more following a negative return than a positive return with the same magnitude. The estimations results for the DCC model for the US, Canada, UK, and France are presented in tables 4 and 5 and figures 3 and 5 . We can see that for all countries the estimates of $\bar{\rho}$ and $b$ are significant in both DCC-GARCH and DCC-EGARCH, whereas the estimates of $a$ are insignificant. A high estimate of the coefficient $b$ indicates the high persistence in correlation.

\subsection{Results}

When we consider an information set which includes lagged volatilities and correlations between US and foreign countries equity returns, we find an association between large volatilities and high correlations. This result is consistent with Ang and Bekaert (2002) observations that correlation is stronger during market turmoil. This relation between the volatility and correlation seems to be asymmetric. In fact, the effect of volatility during market downturn is significantly stronger than its effect during market upturn. However, this asymmetric effect is spurious because the past returns produce asymmetric effects on both volatility and correlation. When we consider the US return effect, the asymmetric effect of volatility disappears. These results suggest that the main determinant of the increase in correlation is the direction of the market movement rather than the volatility of the market. As generally reported for the relationship between return and volatility, 
we find a strong evidence of asymmetric effect of past returns on correlation. We present below a detailed analysis of different relationships.

\subsubsection{Relationship between volatility and correlation}

When the returns effect is not taken into account, the correlation between the US and a foreign country has a high response to US volatility relatively to the volatility of the foreign country [see figures 6-9]. This is particularly true for GARCH filter where US volatility effect is dominant for all countries [see Figure 6]. When the asymmetry between volatility and returns is taken into account through the EGARCH model, the result remains unchanged except for France [see Figure 7]. This association between high volatility and large correlation has been documented by many authors including Ang and Bekaert (2002) in a regime switching model and by Ramchand and Susmel (1998) using a switching ARCH model, where volatility is modeled using ARCH setup and correlation follows a two-regime switching model. In these models it is difficult to distinguish an increase in volatility due to a market downturn from an increase due to a market upturn. Therefore, by separating marginal features from correlation, we are able to extend the analysis to find the impact of market direction on correlation.

\subsubsection{Impact of upturn and downturn volatilities on correlation}

Analyzing the effect of US volatility in different market directions, we find a positive effect associated with market downturn, but a negative or small effect in market upturn (see Figures 10 and 11). This result is consistent with Longin and Solnik (2001) who find a strong exceedance correlation for extreme lower return and no exceedance correlation for extreme upper returns. Using extreme value theory, Longin and Solnik (2001) nicely test correlation during extreme volatile markets between upper return and then between lower returns, while here we use the entire distribution and are able to measure the level of the effect not just for extreme return, but for any value. As we may expect, the effect of volatility on correlation decreases with time horizon. Further, the effect of returns is dominant especially during market downturn.

\subsubsection{Impact of bad and good return news on correlation}

Following the well known feature of GARCH asymmetry which accounts for a difference between the effect of bad news and good news, the similar analysis is performed. While the volatility effects on correlation in downturn and upturn markets are different in term of sign, the returns have clear different effects in terms of the level of the impact. A negative return has a larger 
effect on correlation compared to a positive return of same magnitude (see Figures 12 and 13) . Most importantly, this asymmetric effect of return is the main factor explaining the dynamics of correlation. A bad news increases heavily both volatility and correlation. So the relation between volatility and correlation is not causal, but is driven by the direction of the market. This result clearly gives rise to two observations: (1) there is an association between correlation and volatility, and (2) the correlation strongly increases during market downturn and remains stable during market upturn.

\subsubsection{Testing for asymmetries}

We test for the asymmetric reaction of correlation to volatility and return first separately and then together [see Figures 14-19] ${ }^{7}$ Statistical tests show very relevant results [see Figures 17-19]. Mainly, in the short run, the volatility seems to have an effect on correlation when the return effect is not taken into account. Once the return is introduced as an additional variable in the model, this asymmetric effect becomes not significant. Therefore, the asymmetric effect on correlation is mostly driven by the market return rather than the volatility. With and without volatility, the market return exhibits a strong asymmetry characterized by a strong effect of a negative return and almost no effect of a positive return. The robustness of this result is confirmed by tests using parametric [GARCH and EGARCH both combined with DCC] and nonparametric framework with two different windows $\left[50\right.$ and 70 weeks]. ${ }^{8}$ This result remains stable for different countries.

\subsubsection{Granger causality and association tests}

To confirm the relation between volatility and correlation and then return and correlation, we perform both Granger causality and association tests. Results in Tables 6 and 7 show that volatility does not cause correlation, while return strongly causes correlation. They also show a strong association between volatility and correlation. However, there is no association between return and correlation although a causal relation exists between these two variables.

\subsubsection{Financial gain}

Empirical evidence show the existence of a financial gain from using the asymmetric effect of return on correlation. This gain ranges between 2.15 and 27.50 basis points (bps) for all countries and

\footnotetext{
${ }^{7}$ This asymmetry is the difference between the reaction of correlation during market downturn and market upturn of the same level of volatility or return.

${ }^{8}$ Results for the tests statistics are presented in graphical form to ease the reading and comparison for different horizons. $1 \%$ and $5 \%$ critical values are given and decision can be easily made at these two levels.
} 
for all values of window $m$ and risk aversion $\eta$ and is a decreasing function of the window. When the latter increases the gain decreases. For example, given a risk aversion coefficient $\eta$ equal 5 , the average financial gain of the three countries goes from about 16 bps for $m=30$ to about 4 bps for $m=70$. This can be explained by the fact that when $m$ increases, the asymmetric affect of return on correlation, captured by the coefficient $\theta^{i-}$ in the regression Equation (23), decreases. Table 8 shows that for correlation between the US and Canada, this coefficient changes from 4.9118 to 3.0866 when we increase $m$ from 30 to 70 . For the correlation between US and UK, and US and France, this coefficient changes from 5.6335 to 3.1598 and from 4.2576 to 2.1377 respectively when we increase $m$ from 30 to 70 . In fact, when the window increases, the time variability of correlation decreases and the dynamics is smoother. Another important point to mention is that the financial gain is a decreasing function of the degree of risk aversion. Less risk averse agent outperforms more risk averse agent when both use the asymmetric effect of return on correlation to optimize their portfolio. For example, with a given window $m=50$, the financial gain averages about 12 bps for a risk aversion coefficient of 3 and about 5 bps for a risk aversion coefficient of 7 . In other words, a more aggressive investor takes advantage of the information about the asymmetric behavior of correlation.

\section{Conclusion}

We study the impact of both return and volatility on correlation between international equity markets. The main objective is to determine whether or not there is any asymmetry in correlation and give an explanation for this asymmetry. Within a framework of autoregressive models we quantify the relationship between return, volatility, and correlation using the generalized impulse response function and we test for the asymmetries in the return-correlation and volatility-correlation relationships. We also examine the implications of these asymmetric effects for the optimal international portfolio diversification.

Using weekly data on US, Canada, UK, and France equity indices, empirical evidence show an impact of volatility on correlation. For short and intermediate horizons and without taking into account the effect of returns, we find that the impact of volatility on correlation is asymmetric: volatility seems to have more impact on correlation during market downturn periods than during market upturn periods. However, once we introduce the effect of returns the asymmetric impact of volatility on correlation disappears. This observation suggests that in the presence of return news the asymmetry in the volatility-correlation relationship is spurious since it is absorbed by 
the asymmetric relationship between returns and correlation. These results are confirmed using some tests of the asymmetry in returns-correlation and volatility-correlation relationships with and without considering the returns effect. Therefore, the increase in the correlation is more related to the market direction than the level of volatility. During downturn markets the level of correlation increases and the association between large volatilities and high correlations is mainly due to the simultaneous effect of bad news on both variables. Unlike the potential causal relationship between volatility and correlation suggested by previous literature, we find an association between volatility and correlation which is driven by market direction. Finally, we find that taking into account the asymmetric effect of return on correlation results into a financial gain for international portfolio diversification and that aggressive investors tend to take more advantage from the knowledge of the asymmetric behavior of correlation. Explaining why the market direction drives the correlation is an interesting avenue that should be investigated in future research. 


\section{References}

[1] Ang, A. and G. Bekaert. (2002). "International asset allocation with regime shifts," Review of Financial Studies, 11, 1137-1187.

[2] Ang, A. and J. Chen. (2002). "Asymmetric Correlations of Equity Portfolios," Journal of Financial Economics, 63, 443-494.

[3] Bekaert, G. and G. Wu. (2000). "Asymmetric Volatility and Risk in Equity Markets," Review of Financial Studies, 13, 1-42.

[4] Black, F. (1976). "Studies of Stock Price Volatility Changes," Proceedings of the 1976 Meetings of the American Statistical Association, Business and Economic Statistics, 177-181.

[5] Bollerslev, T. (1986). "Generalized Autoregressive Conditional Heteroskedasticity," Journal of Econometrics, 31, 307-327.

[6] Bollerslev, T., J. Litvinova, and G. Tauchen. (2006). "Leverage and Volatility Feedback Effects in High-Frequency Data," Journal of Financial Econometrics 4 (3), 353-384.

[7] Campbell, J. and L. Hentschel. (1992). "No News is Good News: An Asymmetric Model of Changing Volatility in Stock Returns," Journal of Financial Economics, 31, 281-331.

[8] Cappiello, Lorenzo, Robert F. Engle and Kevin Sheppard (2006), "Asymmetric Dynamics in the Correlations of Global Equity and Bond Returns", Journal of Financial Econometrics 4, 537-572

[9] Christie, A. (1982). "The Stochastic Behavior of Common Stock Variances- Value, Leverage and Interest Rate Effects," Journal of Financial Economics, 3, 145-166.

[10] Doan, T. and R. Litterman. (1983). RATS User's Manual. VAR Econometrics, Minneapolis.

[11] Dufour J-M., R. Garcia, and A. Taamouti. (2008). "Measuring causality between volatility and returns with high frequency data," Universidad Carlos III de Madrid and University of Montreal Working Paper.

[12] Dufour, J.-M., D. Pelletier, and É. Renault. (2006), "Short run and long run causality in time series: Inference," Journal of Econometrics 132(2), 337-362.

[13] Engle, R.F. (2002). "Dynamic Conditional Correlation: A Simple Class of Multivariate Generalized Autoregressive Conditional Heteroskedasticity Models", Journal of Business and Economic Statistics, 20, 339-350. 
[14] Engle, R.F and V.K. Ng. (1993). "Measuring and Testing the Impact of News on Volatility," Journal of Finance, 48, 1749-1778.

[15] French, M., W. Schwert, and R. Stambaugh. (1987). "Expected Stock Returns and Volatility," Journal of Financial Economics, 19, 3-30.

[16] French, M. and J.M. Poterba. (1991). "Investor Diversification and International Equity Markers," American Economic Review, 81, 222-226.

[17] Forbes, K.J. and R. Rigobon. (2002). "No contagion, only interdependence: measuring stock market comovements", Journal of Finance, 57, 2223-2261.

[18] Gallant, A. R. (1987). Nonlinear Statistical Models. John Wiley \& Sons, New York.

[19] Glosten, L. R., R. Jagannathan, and D. E. Runkle. (1993). "On the Relation Between the Expected Value and the Volatility of the Nominal Excess Return on Stocks," Journal of Finance, 48, 1779-1801.

[20] Longin, F. and B. Solnik. (2001). "Extreme correlations in international Equity Markets", Journal of Finance, 56, 649-676.

[21] Nelson, D. B. (1991). "Conditional Heteroskedasticity in Asset Returns: A New Approach," Econometrica, 59, 347-370.

[22] Newey W.K. and D. West. (1987). "A Simple, Positive Semi-Definite, Heteroskedasticity and Autocorrelation Consistent Covariance Matrix," Econometrica, 55, 703-708.

[23] Pindyck, R.S. (1984). "Risk, Inflation, and the Stock Market," American Economic Review, 74, 334-351.

[24] Ramchard, L. and Susmel, R. (1998), "Volatility and Cross Correlation across Major Stocks Markets," Journal of Empirical Finance, 5, 397-416

[25] Schwert, G.W. (1989). "Why Does Stock Market Volatility Change Over Time?" Journal of Finance, 44, 1115-1153.

[26] Turner, C.M., R. Startz, and C.R. Nelson. (1989). "A Markov Model of Heteroskedasticity, Risk and Learning in the Stock Market," Journal of Financial Economics, 25, 3-22. 


\section{Tables and Graphs}

Table 1: Summary statistics for weekly stock returns

\begin{tabular}{|c|c|c|c|c|c|c|c|c|}
\hline Returns & Mean & Median & Max & Min & Std.Dev. & Skewness & Kurtosis & JB \\
\hline$r_{U S}$ & 0.001889 & 0.0037 & 0.1261 & -0.2805 & 0.023989 & -1.683636 & 22.51981 & 17231.21 \\
\hline$r_{\text {Canada }}$ & 0.001459 & 0.00325 & 0.1012 & -0.2453 & 0.024768 & -1.383057 & 13.79779 & 5456.367 \\
\hline$r_{U K}$ & 0.001873 & 0.0023 & 0.1002 & -0.2542 & 0.025856 & -1.101227 & 12.62567 & 4282.064 \\
\hline$r_{\text {France }}$ & 0.002434 & 0.0032 & 0.1403 & -0.1509 & 0.029687 & -0.348288 & 5.739768 & 350.9621 \\
\hline \multicolumn{9}{|c|}{ Correlations } \\
\hline \multirow{4}{*}{$\begin{array}{l}\text { Canada } \\
\text { UK } \\
\text { France }\end{array}$} & US & Canada & UK & & & & & \\
\hline & 0.7133 & & & & & & & \\
\hline & 0.5520 & 0.5406 & & & & & & \\
\hline & 0.5315 & 0.5041 & 0.6363 & & & & & \\
\hline
\end{tabular}

Note: This table summarizes the weekly returns characteritics for the US, Canada, UK, and France equity indices and the correlation between them. In this table $J B$ represents the Jarque-Bera test statistic. The sample covers the period from October 16th 1984 to December 21th 2004 for a total of 1054 observations.

Table 2: Parameter estimates for GARCH model

\begin{tabular}{lcccc}
\hline Country & $\mu$ & $\omega\left(10^{-6}\right)$ & $\beta$ & $\alpha$ \\
\hline \multirow{2}{*}{ US } & 0.0024 & 4.09 & 0.9197 & 0.0803 \\
& {$[0.0006]$} & {$[2.00]$} & {$[0.0095]$} & {$[0.0124]$} \\
Canada & 0.0017 & 14.00 & 0.9195 & 0.0613 \\
& {$[0.0008]$} & {$[4.00]$} & {$[0.0126]$} & {$[0.0106]$} \\
\multirow{2}{*}{ UK } & 0.0017 & 5.00 & 0.9569 & 0.0362 \\
& {$[0.0007]$} & {$[3.00]$} & {$[0.0081]$} & {$[0.0074]$} \\
\multirow{2}{*}{ France } & 0.0027 & 30.00 & 0.8714 & 0.0943 \\
& {$[0.0009]$} & {$[10.00]$} & {$[0.0250]$} & {$[0.0172]$} \\
\hline
\end{tabular}

Note: This table summarizes the estimation results of parametric $G A R C H$ model in Equations (1) and (2). The standard errors are in brackets below the estimates. 
Table 3: Parameter estimates for EGARCH model

\begin{tabular}{lccccc}
\hline Country & $\mu$ & $\omega$ & $\beta$ & $\alpha$ & $c$ \\
\hline \multirow{2}{*}{ US } & 0.0017 & -0.1434 & 0.9802 & 0.1592 & -0.0699 \\
& {$[0.0007]$} & {$[0.0498]$} & {$[0.0067]$} & {$[0.0298]$} & {$[0.0208]$} \\
Canada & 0.0017 & -0.7288 & 0.9015 & 0.2453 & -0.1197 \\
& {$[0.0007]$} & {$[0.1434]$} & {$[0.019]$} & {$[0.0390]$} & {$[0.0145]$} \\
\multirow{2}{*}{ UK } & 0.0019 & -0.0241 & 0.9964 & 0.0711 & 0.0023 \\
& {$[0.0008]$} & {$[0.0227]$} & {$[0.0032]$} & {$[0.0120]$} & {$[0.0053]$} \\
\multirow{2}{*}{ France } & 0.0023 & -0.2820 & 0.9598 & 0.2012 & -0.0421 \\
& {$[0.0008]$} & {$[0.1012]$} & {$[0.0143]$} & {$[0.0320]$} & {$[0.0134]$} \\
\hline
\end{tabular}

Note: This table summarizes the estimation results of parametric $E G A R C H$ model in Equations (1) and (3). The standard errors are in brackets below the estimates.

Table 4: Parameter estimates for DCC, filtered using GARCH model

\begin{tabular}{lccc}
\hline & $\bar{\rho}$ & $b$ & $a$ \\
\hline \multirow{2}{*}{ US - Canada } & 0.7060 & 0.9227 & 0.0435 \\
& {$[0.022]$} & {$[0.0042]$} & {$[0.0059]$} \\
US -UK & 0.5267 & 0.8306 & 0.0337 \\
& {$[0.0263]$} & {$[0.0277]$} & {$[0.0191]$} \\
US - France & 0.4935 & 0.9872 & 0.0130 \\
& {$[0.0269]$} & {$[0.0176]$} & {$[0.0156]$} \\
\hline
\end{tabular}

Note: This table summarizes the estimation results of parametric $D C C-G A R C H$ model in equations (4) and (5). The standard errors are in brackets below the estimates.

Table 5: Parameter estimates for DCC, filtered using EGARCH model

\begin{tabular}{lccc}
\hline & $\bar{\rho}$ & $b$ & $a$ \\
\hline \multirow{2}{*}{ US - Canada } & 0.6848 & 0.8444 & 0.0677 \\
& {$[0.0224]$} & {$[0.0618]$} & {$[0.0572]$} \\
US -UK & 0.5174 & 0.9656 & 0.0120 \\
& {$[0.0264]$} & {$[0.0249]$} & {$[0.0393]$} \\
US - France & 0.4762 & 0.9943 & 0.0206 \\
& {$[0.0271]$} & {$[0.0556]$} & {$[0.0493]$} \\
\hline
\end{tabular}

Note: This table summarizes the estimation results of parametric $D C C$-EGARCH model in equations (4) and (5). The standard errors are in brackets below the estimates. 
Table 6: Association and Granger causality between US volatility and correlation

\begin{tabular}{l|ccccccc}
\hline & \multicolumn{7}{|c}{ P-values } \\
& \multirow{2}{*}{ Association } & \multicolumn{7}{c}{ Causality for order } \\
\cline { 2 - 8 } Panel I $: m=30$ & & $p=1$ & $p=2$ & $p=5$ & $p=10$ & $p=15$ & $p=20$ \\
\cline { 2 - 8 } & & & & & & & \\
US-Canada & 0.0000 & 0.0699 & 0.1730 & 0.1354 & 0.1039 & 0.2223 & 0.4422 \\
US-UK & 0.0000 & 0.0288 & 0.0517 & 0.2350 & 0.2693 & 0.4563 & 0.6874 \\
US-France & 0.0000 & 0.1236 & 0.3055 & 0.7895 & 0.7281 & 0.5133 & 0.4958 \\
& & & & & & & \\
Panel II : $m=50$ & & & & & & & \\
& & & & & & & \\
US-Canada & 0.0000 & 0.2375 & 0.3118 & 0.3345 & 0.2461 & 0.2820 & 0.4856 \\
US-UK & 0.0000 & 0.0391 & 0.0974 & 0.3354 & 0.5567 & 0.5567 & 0.3771 \\
US-France & 0.0000 & 0.1762 & 0.3953 & 0.6643 & 0.6406 & 0.4138 & 0.6576 \\
& & & & & & & \\
Panel III : $m=70$ & & & & & & & \\
US-Canada & 0.0000 & 0.2222 & 0.3757 & 0.7001 & 0.6168 & 0.4559 & 0.6634 \\
US-UK & 0.0000 & 0.0212 & 0.0678 & 0.2846 & 0.2650 & 0.0935 & 0.1313 \\
US-France & 0.0000 & 0.1236 & 0.3113 & 0.5775 & 0.4711 & 0.2723 & 0.3990 \\
\hline
\end{tabular}

Note: This table summarizes the results of the association and Granger causality tests from the US volatility to correlation between US and foreign equity returns. $m$ is the window in the nonparametric estimation of volatility and correlation. To test the association between US volatility and correlation we consider the following regression model, for $i=$ Canada, UK, France,

$$
l\left(\rho_{i, t}\right)=\mu_{\sigma}+\gamma_{\sigma} \ln \left(\sigma_{U S, t}^{2}\right)+u_{t} .
$$

The null hypothesis in this case is: $\quad H_{0}: \gamma_{\sigma}=0$.

To test Granger causality from US volatility to correlation we consider the following model, for $i=$ Canada, $U K$, France,

$$
l\left(\rho_{i, t}\right)=\phi_{0}^{\sigma}+\sum_{j=1}^{p} \phi_{j}^{\sigma} l\left(\rho_{i, t-j}\right)+\sum_{j=1}^{p} \alpha_{j}^{\sigma} \ln \left(\sigma_{U S, t-j}^{2}\right)+u_{t}, \text { for } p \geq 1 .
$$

The null hypothesis in this case is: $\quad H_{0}: \alpha_{1}^{\sigma}=\ldots=\alpha_{p}^{\sigma}=0$. 
Table 7: Association and Granger causality between US returns and correlation

\begin{tabular}{l|ccccccc}
\hline & \multicolumn{7}{|c}{ P-values } \\
\hline & \multirow{2}{*}{ Association } & \multicolumn{7}{c}{ Causality for order } \\
\cline { 2 - 7 } Panel I $: m=30$ & & $p=1$ & $p=2$ & $p=5$ & $p=10$ & $p=15$ & $p=20$ \\
\cline { 2 - 7 } & & & & & & & \\
US-Canada & 0.4539 & $2.10^{-16}$ & $3.10^{-16}$ & $1.10^{-14}$ & $3.10^{-13}$ & $7.10^{-12}$ & $2.10^{-10}$ \\
US-UK & 0.7396 & $3.10^{-7}$ & $4.10^{-8}$ & $2.10^{-6}$ & $7.10^{-6}$ & $9.10^{-5}$ & 0.0002 \\
US-France & 0.3979 & $6.10^{-13}$ & $1.10^{-12}$ & $2.10^{-11}$ & $1.10^{-9}$ & $8.10^{-9}$ & $3.10^{-7}$ \\
& & & & & & & \\
Panel II : $m=50$ & & & & & & & \\
& & & & & & & \\
US-Canada & 0.4377 & $1.10^{-14}$ & $3.10^{-14}$ & $5.10^{-14}$ & $2.10^{-12}$ & $5.10^{-12}$ & $1.10^{-11}$ \\
US-UK & 0.6849 & $2.10^{-11}$ & $1.10^{-11}$ & $8.10^{-10}$ & $4.10^{-8}$ & $2.10^{-7}$ & $2.10^{-7}$ \\
US-France & 0.9671 & $2.10^{-15}$ & $2.10^{-15}$ & $1.10^{-14}$ & $7.10^{-12}$ & $1.10^{-10}$ & $9.10^{-10}$ \\
& & & & & & & \\
Panel III : $m=70$ & & & & & & & \\
US-Canada & & & & & & & \\
US-UK & 0.4632 & $1.10^{-14}$ & $9.10^{-14}$ & $4.10^{-13}$ & $2.10^{-11}$ & $2.10^{-10}$ & $2.10^{-9}$ \\
US-France & 0.5809 & $2.10^{-11}$ & $6.10^{-11}$ & $8.10^{-10}$ & $3.10^{-8}$ & $6.10^{-7}$ & $3.10^{-6}$ \\
\hline
\end{tabular}

Note: This table summarizes the results of the association and Granger causality tests from the US returns to correlation between US and foreign equity returns. $m$ is the window in the nonparametric estimation of correlation. To test the association between US returns and correlation we consider the following regression model, for $i=$ Canada, UK, France,

$$
l\left(\rho_{i, t}\right)=\mu_{r}+\gamma_{r} \operatorname{Re}_{U S, t}+u_{t} .
$$

The null hypothesis in this case is: $\quad H_{0}: \gamma_{r}=0$.

To test Granger causality from US returns to correlation we consider the following model, for $i=$ Canada, UK, France,

$$
l\left(\rho_{i, t}\right)=\phi_{0}^{r}+\sum_{j=1}^{p} \phi_{j}^{r} l\left(\rho_{i, t-j}\right)+\sum_{j=1}^{p} \alpha_{j}^{r} \operatorname{Re}_{U S, t-j}+u_{t}, \text { for } p \geq 1 .
$$

The null hypothesis in this case is: $\quad H_{0}: \alpha_{1}^{r}=\ldots=\alpha_{p}^{r}=0$. 
Table 8: Estimates of the parameters of the regression model with asymmetric effect of return on correlation

\begin{tabular}{|c|c|c|c|}
\hline & $\overline{U S-C a n a d a}$ & $U S-U K$ & $U S-$ France \\
\hline \multicolumn{4}{|l|}{$m=30$} \\
\hline$\lambda^{i}$ & $\begin{array}{c}0.0079 \\
(0.7330)\end{array}$ & $\begin{array}{c}-0.0045 \\
(-0.4480)\end{array}$ & $\begin{array}{c}-0.0029 \\
(-0.3561)\end{array}$ \\
\hline$\xi^{i}$ & $\begin{array}{c}0.9698 \\
(134.9092)\end{array}$ & $\begin{array}{c}0.9604 \\
(87.3875)\end{array}$ & $\begin{array}{c}0.9710 \\
(139.3162)\end{array}$ \\
\hline$\theta^{i-}$ & $\begin{array}{c}4.9118 \\
(5.3334)\end{array}$ & $\begin{array}{c}5.6335 \\
(3.3993)\end{array}$ & $\begin{array}{c}4.2576 \\
(4.3852)\end{array}$ \\
\hline$\theta^{i}$ & $\begin{array}{c}1.5884 \\
(4.5431)\end{array}$ & $\begin{array}{c}2.3198 \\
(4.3185)\end{array}$ & $\begin{array}{c}1.3697 \\
(3.3907)\end{array}$ \\
\hline \multicolumn{4}{|l|}{$m=50$} \\
\hline$\lambda^{i}$ & $\begin{array}{c}0.0026 \\
(0.2919)\end{array}$ & $\begin{array}{c}-0.0077 \\
(-0.9361)\end{array}$ & $\begin{array}{c}-0.0059 \\
(-0.9982)\end{array}$ \\
\hline$\xi^{i}$ & $\begin{array}{c}0.9798 \\
(146.2465)\end{array}$ & $\begin{array}{c}0.9751 \\
(108.9811)\end{array}$ & $\begin{array}{c}0.9846 \\
(206.7533)\end{array}$ \\
\hline$\theta^{i-}$ & $\begin{array}{c}3.6875 \\
(3.5114)\end{array}$ & $\begin{array}{c}4.3144 \\
(3.0475)\end{array}$ & $\begin{array}{c}2.8757 \\
(3.5658)\end{array}$ \\
\hline$\theta^{i}$ & $\begin{array}{c}1.2577 \\
(3.6345)\end{array}$ & $\begin{array}{c}1.6464 \\
(3.8912)\end{array}$ & $\begin{array}{c}0.8854 \\
(2.9863)\end{array}$ \\
\hline \multicolumn{4}{|l|}{$m=70$} \\
\hline$\lambda^{i}$ & $\begin{array}{c}0.0022 \\
(0.2606)\end{array}$ & $\begin{array}{c}-0.0039 \\
(-0.4824)\end{array}$ & $\begin{array}{c}-0.0079 \\
(-1.7239)\end{array}$ \\
\hline$\xi^{i}$ & $\begin{array}{c}0.9833 \\
(157.8482)\end{array}$ & $\begin{array}{c}0.9811 \\
(126.0176)\end{array}$ & $\begin{array}{c}0.9918 \\
(274.3590)\end{array}$ \\
\hline$\theta^{i-}$ & $\begin{array}{c}3.0866 \\
(3.1941)\end{array}$ & $\begin{array}{c}3.1598 \\
(2.8241)\end{array}$ & $\begin{array}{c}2.1377 \\
(3.8354)\end{array}$ \\
\hline$\theta^{i}$ & $\begin{array}{c}1.0501 \\
(3.5108)\end{array}$ & $\begin{array}{c}1.1551 \\
(3.5023)\end{array}$ & $\begin{array}{c}0.6366 \\
(2.9912)\end{array}$ \\
\hline
\end{tabular}

Note: This table summarizes the estimation results of the coefficients in the following regression model:

$$
l\left(\rho_{i, t}\right)=\lambda^{i}+\xi^{i} l\left(\rho_{i, t-1}\right)+\theta^{i-} \cdot \mathbb{I}_{t-1}^{-} \operatorname{Re}_{U S, t-1}+\theta^{i} \operatorname{Re}_{U S, t-1}+e_{t}^{i} .
$$

We first calculate the correlations between US and foreign country $i$ returns using the nonparametric approach described in Section (2.2), and then we use regression model in (24) to estimation the correlations as function of its own past and past of returns. The number in parentheses show the test-statistics of the corresponding coefficient based on Newey-West estimator of the variancecovariance matrix. 
Table 9: Estimates of the parameters of the regression model without asymmetric effect of return on correlation

\begin{tabular}{|c|c|c|c|}
\hline & $\overline{U S-C a n a d a}$ & $U S-U K$ & $U S-$ France \\
\hline \multicolumn{4}{|l|}{$m=30$} \\
\hline$\lambda^{i}$ & $\begin{array}{c}0.0317 \\
(2.7764)\end{array}$ & $\begin{array}{c}0.0336 \\
(2.5845)\end{array}$ & $\begin{array}{c}0.0264 \\
(2.8975)\end{array}$ \\
\hline$\xi^{i}$ & $\begin{array}{c}0.9816 \\
(144.4308)\end{array}$ & $\begin{array}{c}0.9709 \\
(92.3637)\end{array}$ & $\begin{array}{c}0.9784 \\
(140.0580)\end{array}$ \\
\hline$\theta^{i}$ & $\begin{array}{l}-1.1845 \\
(-2.2340)\end{array}$ & $\begin{array}{l}-0.8575 \\
(-1.0845)\end{array}$ & $\begin{array}{l}-1.0339 \\
(-2.0224)\end{array}$ \\
\hline \multicolumn{4}{|l|}{$m=50$} \\
\hline$\lambda^{i}$ & $\begin{array}{c}0.0199 \\
(2.0211)\end{array}$ & $\begin{array}{c}0.0225 \\
(2.0994)\end{array}$ & $\begin{array}{c}0.0146 \\
(2.1644)\end{array}$ \\
\hline$\xi^{i}$ & $\begin{array}{c}0.9890 \\
(167.4178)\end{array}$ & $\begin{array}{c}0.9822 \\
(114.2281)\end{array}$ & $\begin{array}{c}0.9891 \\
(205.6300)\end{array}$ \\
\hline$\theta^{i}$ & $\begin{array}{c}-0.8273 \\
(-1.6526)\end{array}$ & $\begin{array}{l}-0.7905 \\
(-1.2163)\end{array}$ & $\begin{array}{c}-0.7377 \\
(-1.8812)\end{array}$ \\
\hline \multicolumn{4}{|l|}{$m=70$} \\
\hline$\lambda^{i}$ & $\begin{array}{c}0.0158 \\
(1.7981)\end{array}$ & $\begin{array}{c}0.0180 \\
(2.0989)\end{array}$ & $\begin{array}{c}0.0079 \\
(1.6584)\end{array}$ \\
\hline$\xi^{i}$ & $\begin{array}{c}0.9914 \\
(182.7960)\end{array}$ & $\begin{array}{c}0.9864 \\
(134.4640)\end{array}$ & $\begin{array}{c}0.9946 \\
(272.9256)\end{array}$ \\
\hline$\theta^{i}$ & $\begin{array}{c}-0.6987 \\
(-1.5547)\end{array}$ & $\begin{array}{l}-0.6336 \\
(-1.2544)\end{array}$ & $\begin{array}{c}-0.5727 \\
(-2.0368)\end{array}$ \\
\hline
\end{tabular}

Note: This table summarizes the estimation results of the coefficients in the following regression model:

$$
l\left(\rho_{i, t}\right)=\lambda^{i}+\xi^{i} l\left(\rho_{i, t-1}\right)+\theta^{i} \operatorname{Re}_{U S, t-1}+e_{t}^{i}
$$

We first calculate the correlations between US and foreign country $i$ returns using the nonparametric approach described in Section (2.2), and then we use regression model in (25) to estimation correlations as function of its own past and past of returns. The number in parentheses show the test-statistics of the corresponding coefficient based on Newey-West estimator of the variancecovariance matrix. 
Table 10: Financial Gain of Using the Asymmetric Effect of Return on Correlation

\begin{tabular}{|c|c|c|c|}
\hline & $\eta=3$ & $\eta=5$ & $\eta=7$ \\
\hline \multicolumn{4}{|l|}{$m=30$} \\
\hline US - Canada & 27.4839 & 17.0693 & 12.5687 \\
\hline$U S-U K$ & 25.3924 & 15.9761 & 11.8646 \\
\hline US - France & 25.9325 & 15.9600 & 11.5916 \\
\hline \multicolumn{4}{|l|}{$m=50$} \\
\hline US - Canada & 14.7173 & 8.9056 & 6.3590 \\
\hline$U S-U K$ & 11.3433 & 6.9592 & 4.9979 \\
\hline$U S-$ France & 10.0167 & 5.9345 & 4.1035 \\
\hline \multicolumn{4}{|l|}{$m=70$} \\
\hline US - Canada & 8.9857 & 5.5357 & 3.9931 \\
\hline$U S-U K$ & 6.4332 & 3.9327 & 2.7869 \\
\hline US - France & 5.4726 & 3.1952 & 2.1485 \\
\hline
\end{tabular}

Note: This table summarizes the estimation results of average financial gain of using the asymmetric effect of return on correlation. All values are the average over the time-period expressed in annualized basis points. $m$ is the windows in the nonparametric estimation of correlation and $\eta$ is the risk aversion coefficient 
Figure 1: US, Canada, UK, France, Equity Returns, 1984-2004

US equity returns, 1984-2004

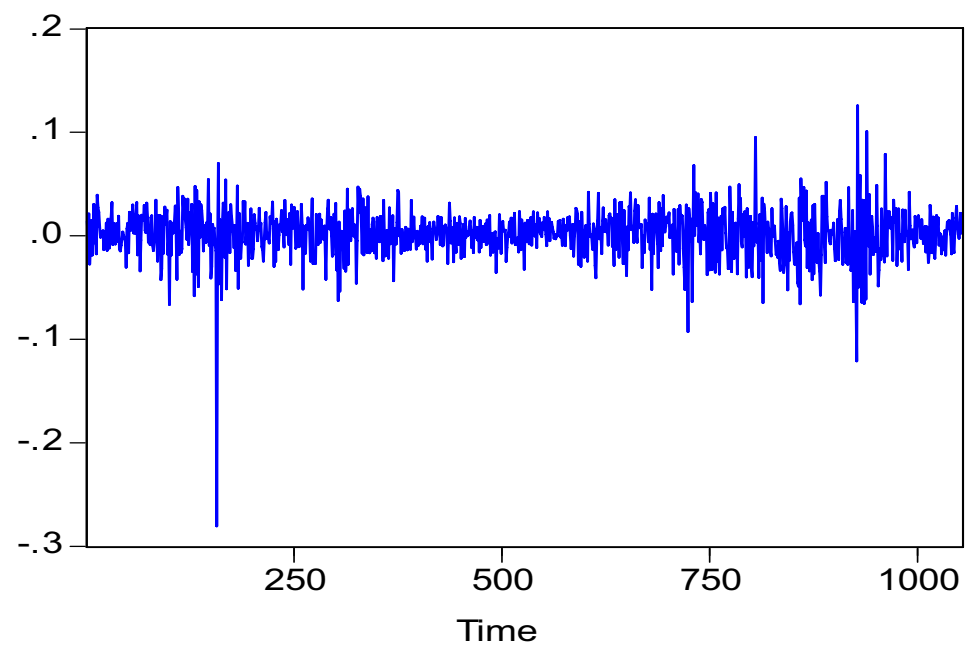

UK equity returns, 1984-2004

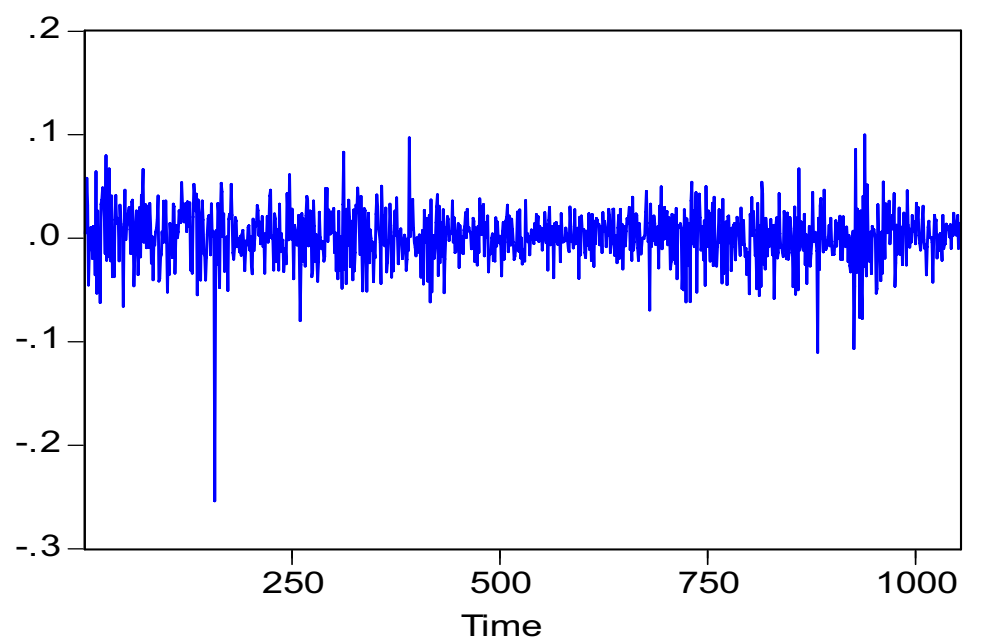

Canada equity returns, 1984-2004

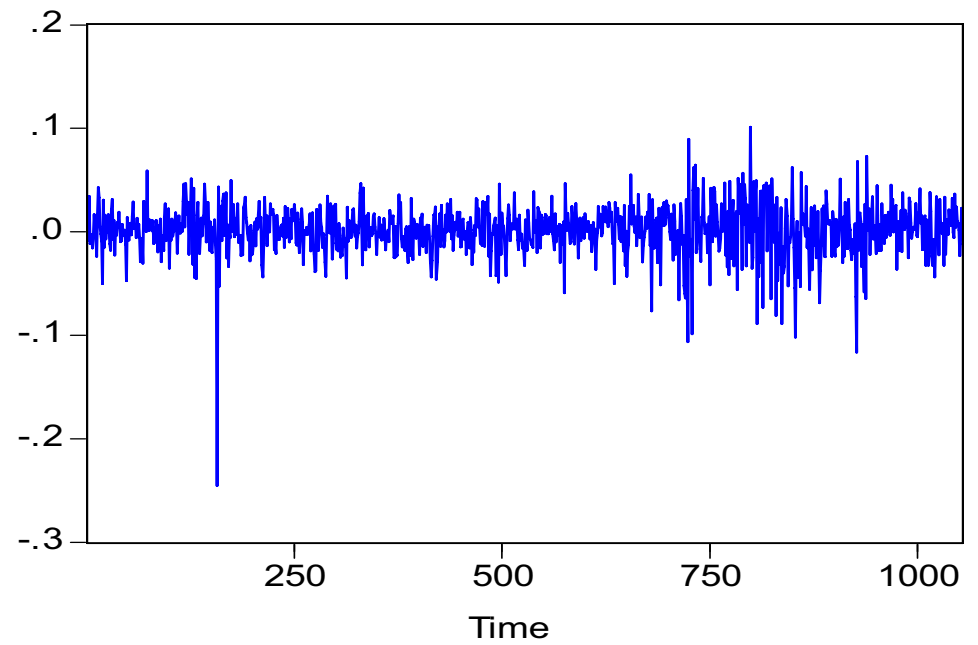

France equity returns, 1984-2004

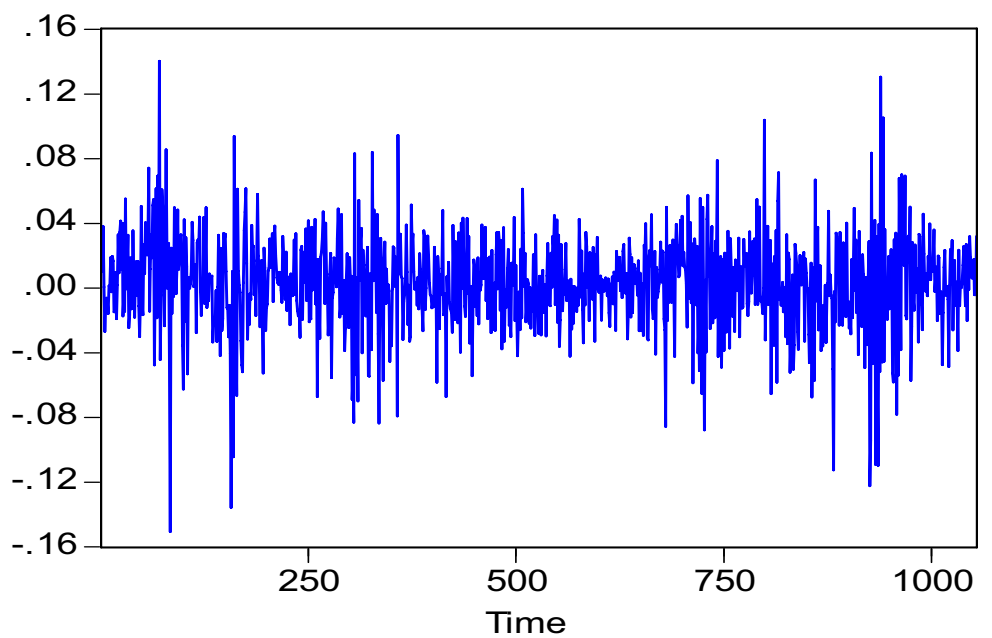

These graphs represent weekly equity returns in US, Canada, UK, and France. The sample covers the period from October 16 th 1984 to December 21 th 2004 for total of 1054 observations. 
Figure 2: US, Canada, UK, France GARCH Volatilities, 1984-2004

US equity returns GARCH Volatility, 1984-2004

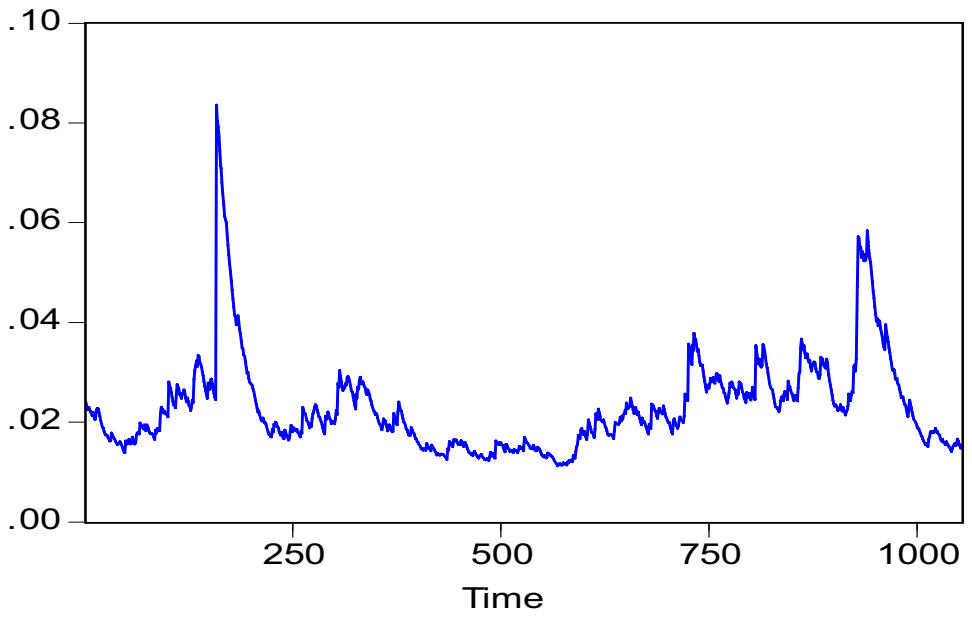

UK equity returns GARCH Volatility, 1984-2004

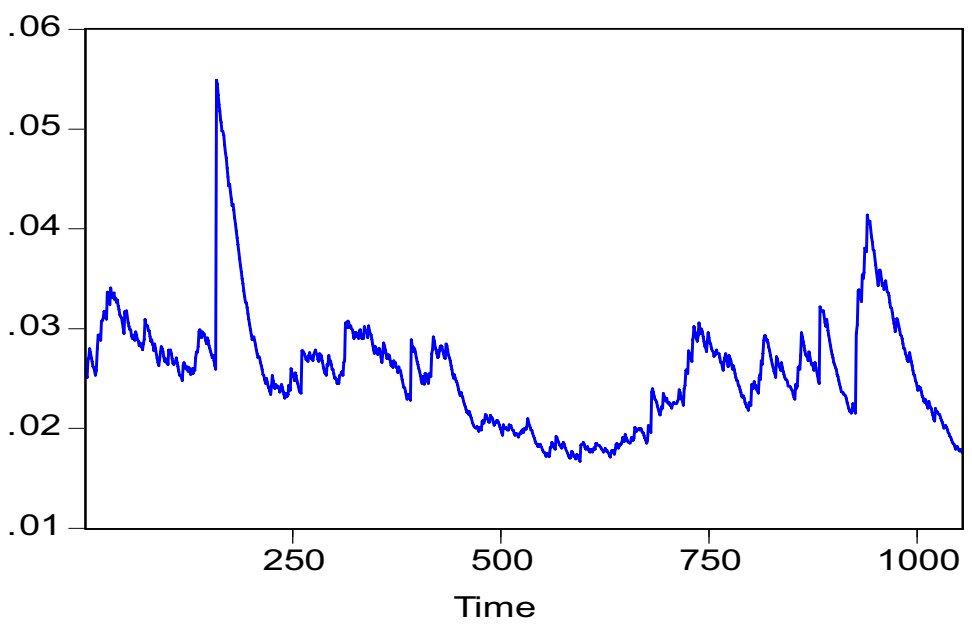

Canada equity returns GARCH Volatility, 1984-2004

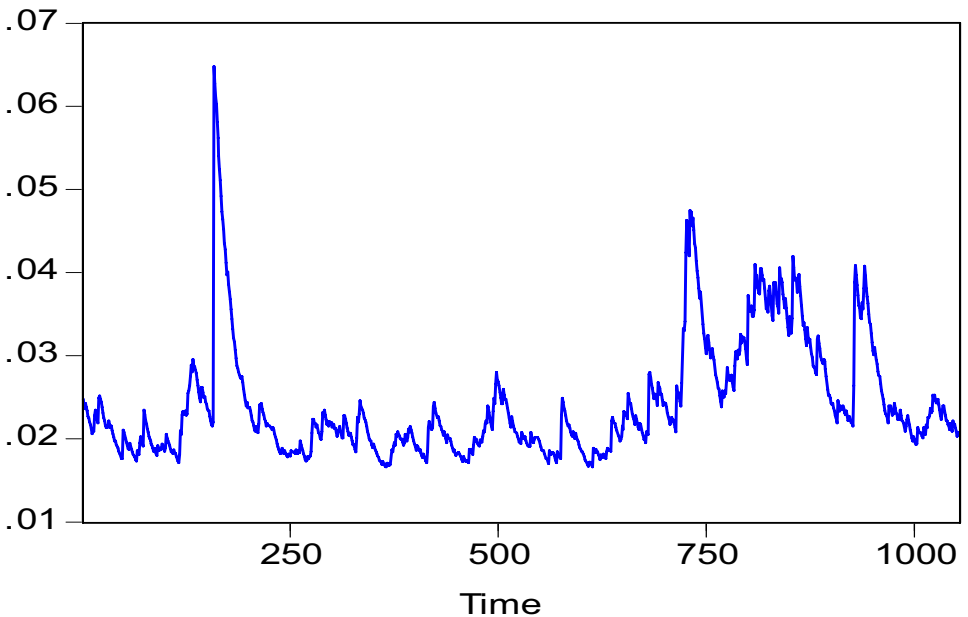

France equity returns GARCH Volatility, 1984-2004

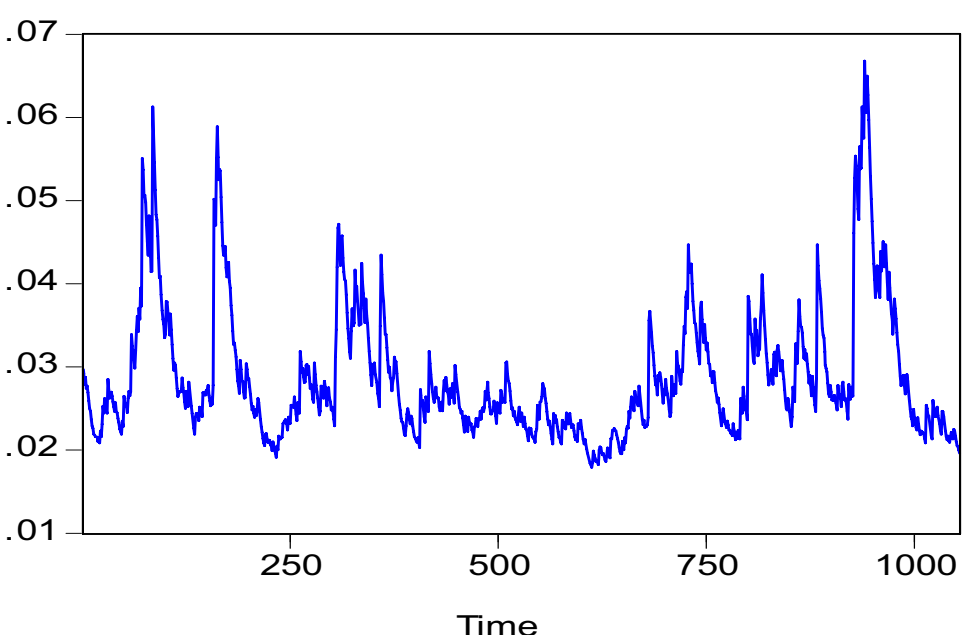

These graphs represent weekly equity return GARCH volatilities in US, Canada, UK, and France. The sample covers the period from October 16th 1984 to December 21th 2004 for total of 1054 observations. 
Figure 3: US-Canada, US-UK, US-France DCC-GARCH Correlations, 1984-2004

Correlation betw een US and Canada: GARCH+DCC

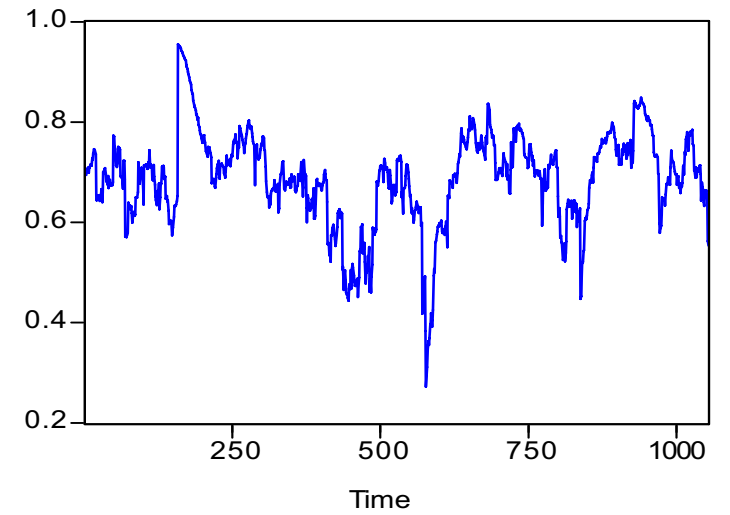

Correlation betw een US and UK: GARCH+DCC

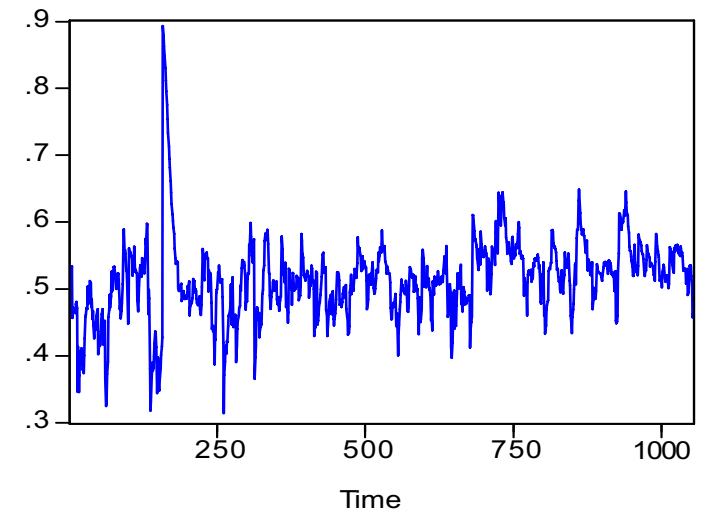

Correlation betw een US and France: GARCH+DCC

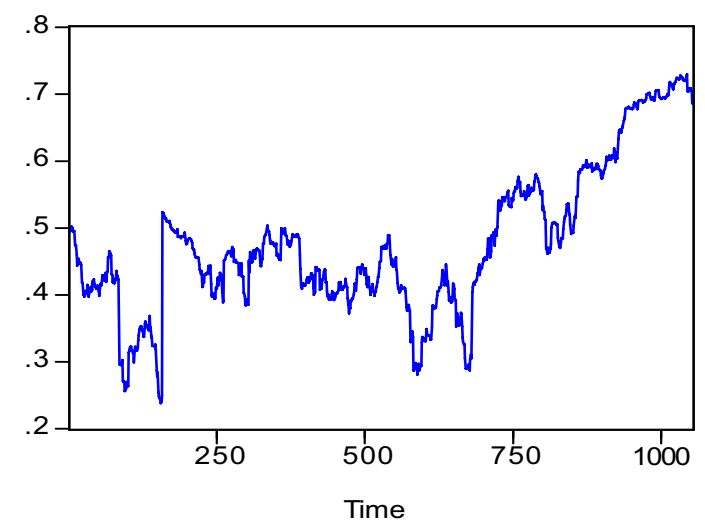

These graphs represent weekly DCC-GARCH correlations between US and Canada returns, US and UK returns, and US and France returns. The sample covers the period from October 16th 1984 to December 21th 2004 for total of 1054 observations. 
Figure 4: US, Canada, UK, France, EGARCH Volatilities, 1984-2004

US equity returns EGARCH Volatility, 1984-2004

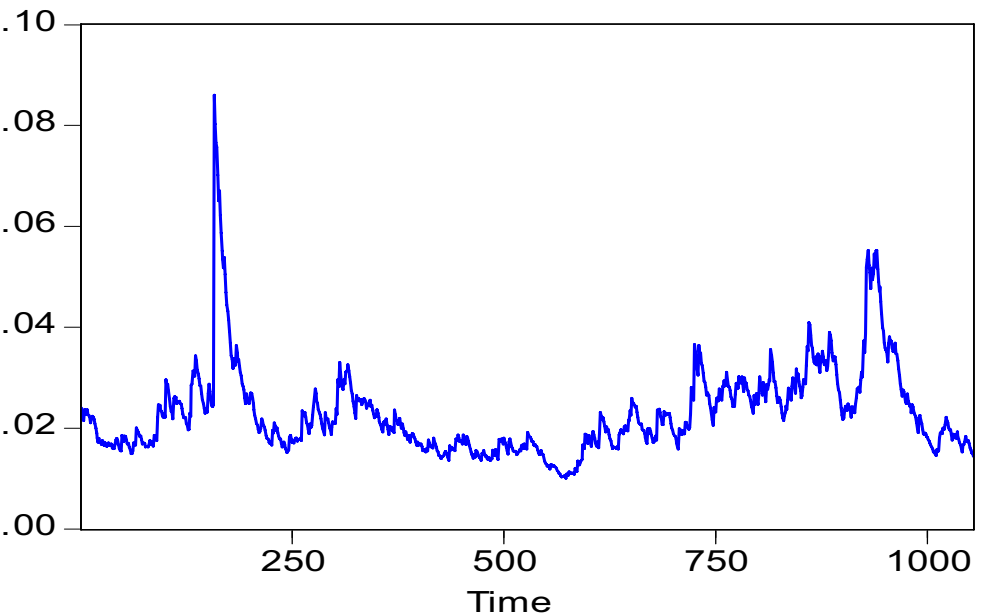

UK equity returns EGARCH Volatility, 1984-2004

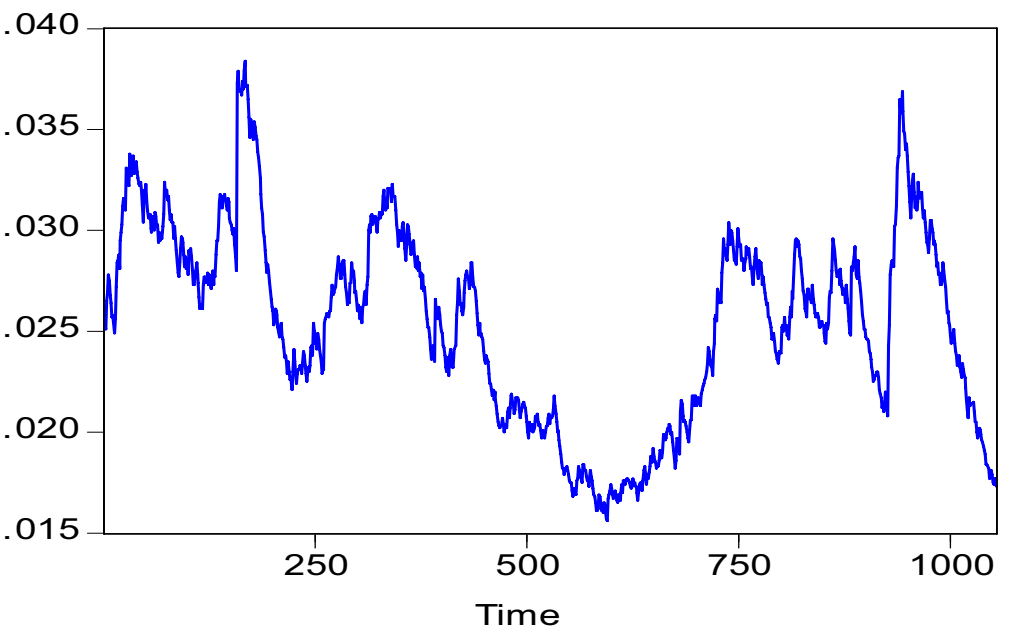

Canada equity returns EGARCH Volatility, 1984-2004

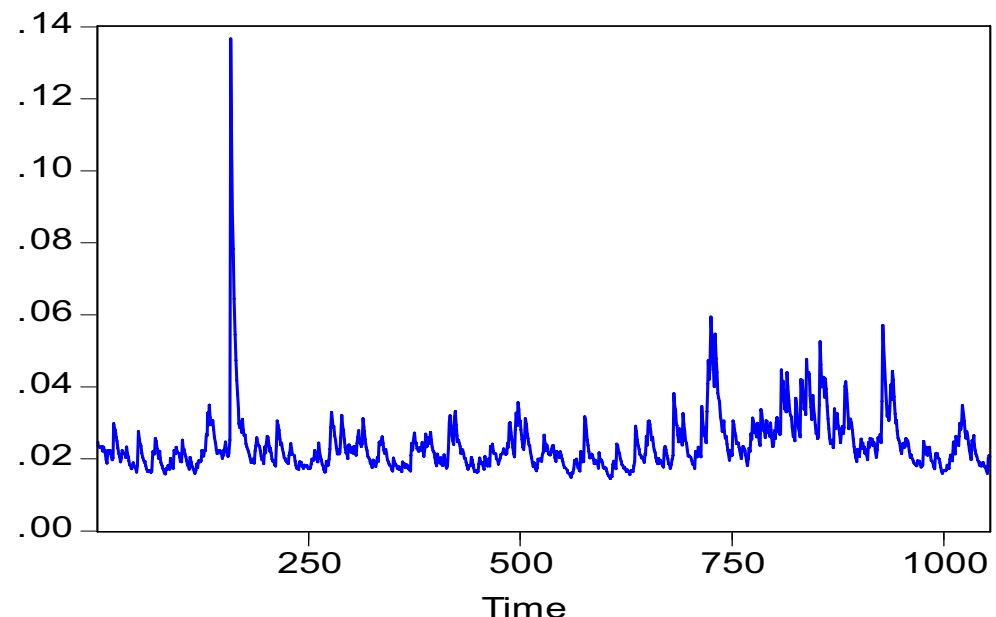

France equity returns EGARCH Volatility, 1984-2004

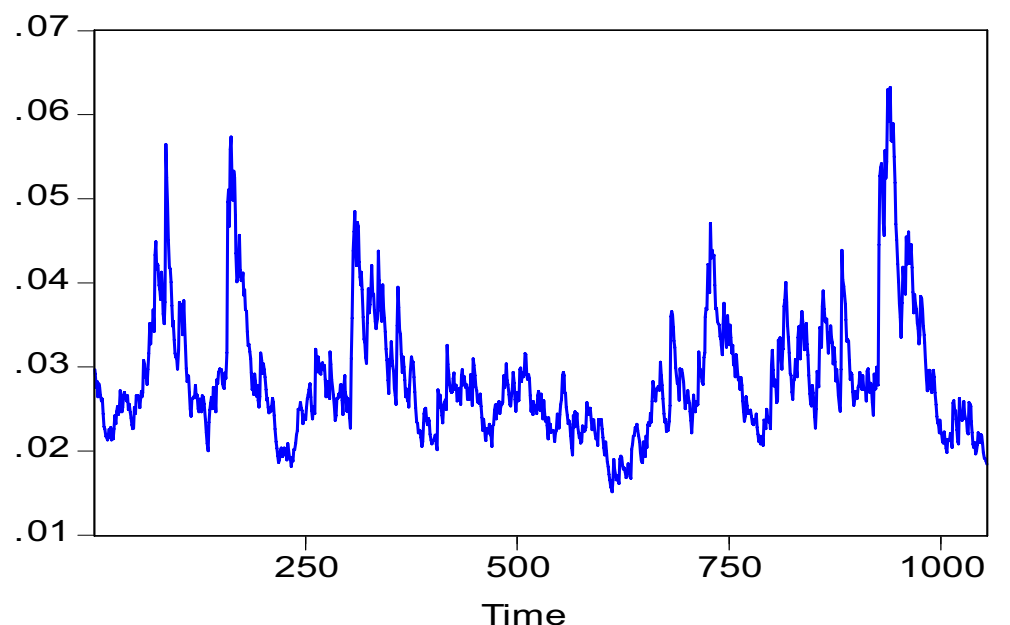

These graphs represent weekly equity return EGARCH volatilities in US, Canada, UK, and France. The sample covers the period from October 16th 1984 to December 21th 2004 for total of 1054 observations. 
Figure 5: US-Canada, US-UK, US-France DCC-EGARCH Correlations, 1984-2004

Correlation between US and Canada: EGARCH+DCC

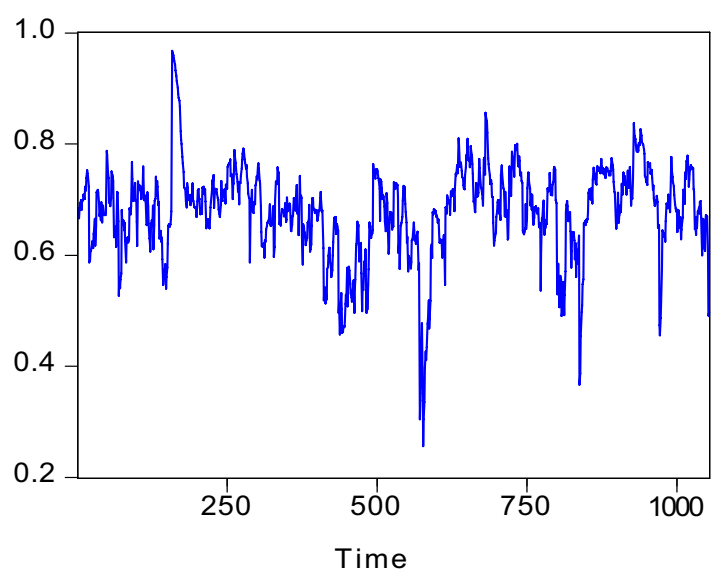

Correlation between US and UK: EGARCH+DCC

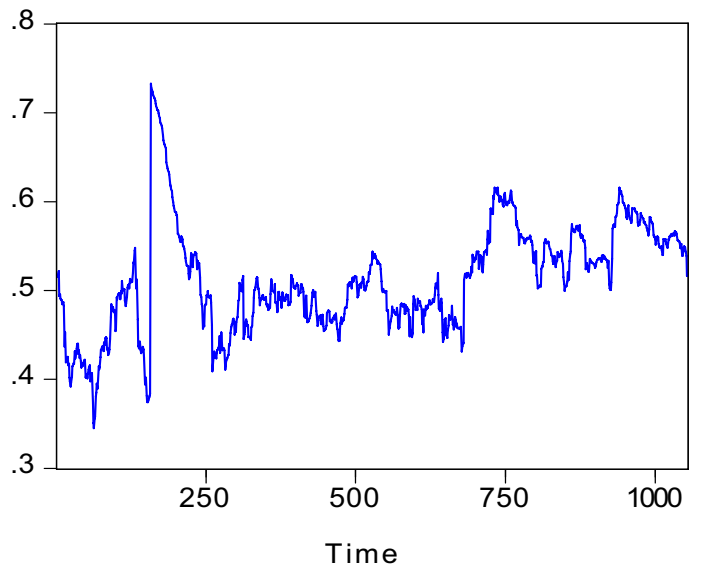

Correlation between US and France: EGARCH+DCC

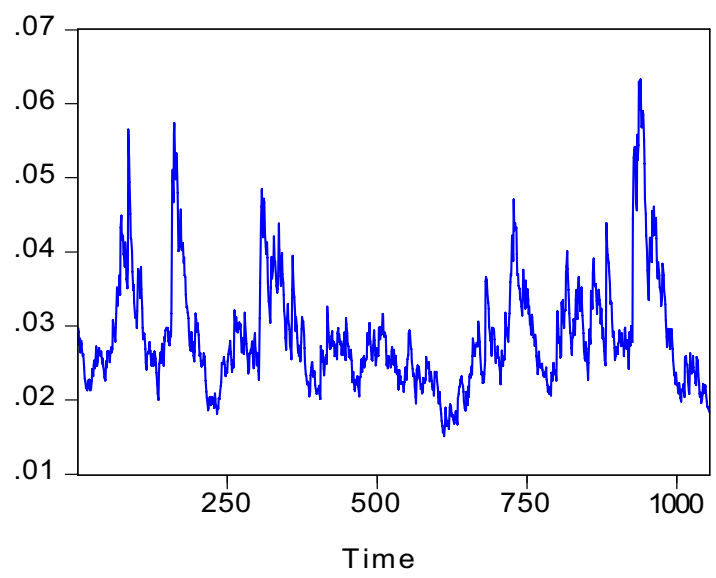

These graphs represent weekly DCC-EGARCH correlations between US and Canada returns, US and UK returns, and US and France returns. The sample covers the period from October 16th 1984 to December 21th 2004 for total of 1054 observations. 


\section{Figure 6: Impact of GARCH Volatilities on Correlations}

Response of Correlation between US and Canada Returns to Volatilities

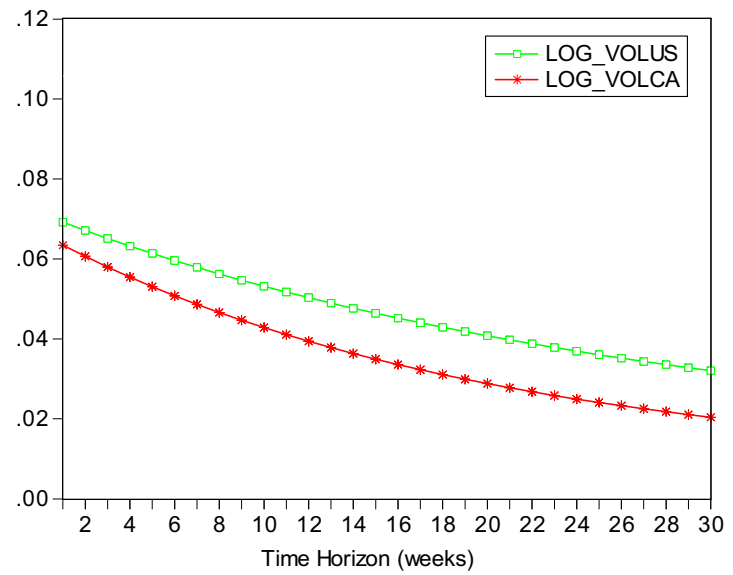

Response of Correlation between US and France Returns to Volatilities

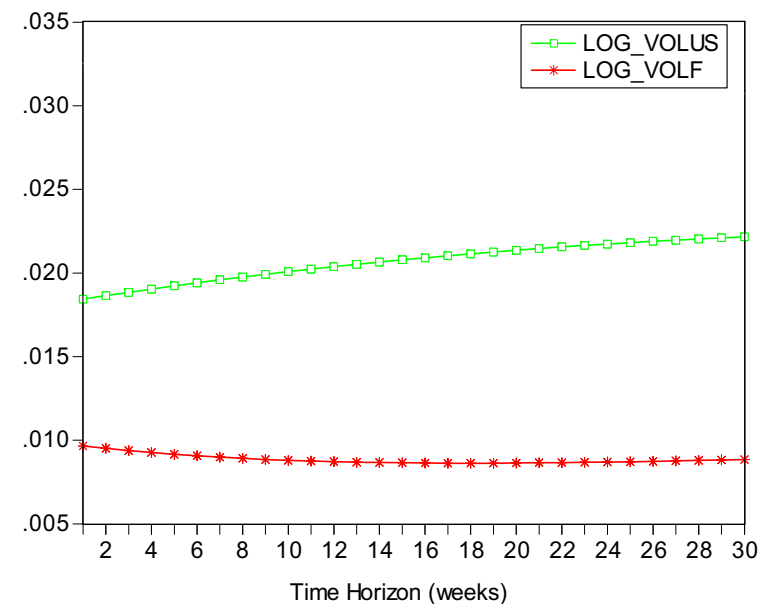

Response of Correlation between US and UK Returns to Volatilities

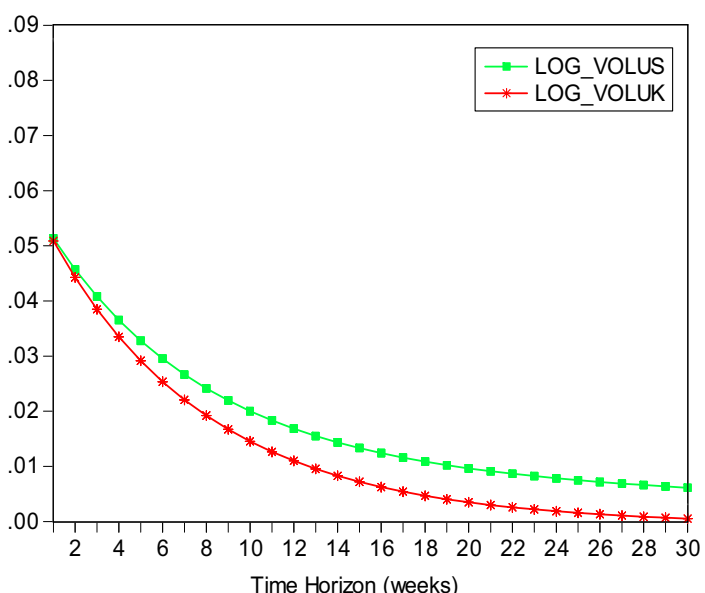

Response of Correlation between US and France Returns to Volatilities, EC model

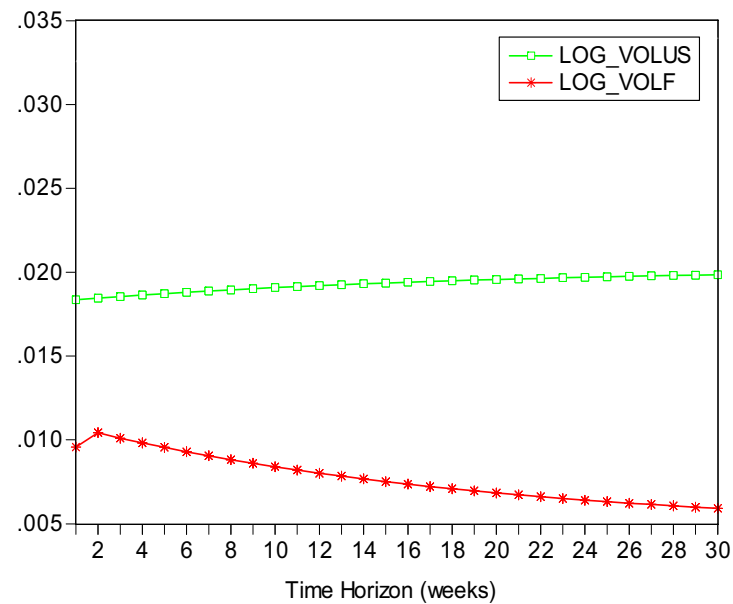

These graphs use the US, Canada, UK, and France volatilities obtained from the GARCH $(1,1)$. The correlations US-Canada, US-UK, and US-France used for graphs are filtered from DCC model using the respective volatilities. In each graph, "LOG_VOLUS" is the curve representing the response of correlations to US volatility, while "LOG_VOLUCA" is the response of US-Canada correlation to Canada volatility, "LOG VOLUCA" is the response of US-UK correlation to UK volatility, and "LOG VOLUF" is the response of US-France correlation to France volatility. 
Figure 7: Impact of EGARCH Volatilities on Correlations

Response of Correlation between US and Canada Returns to Volatilities

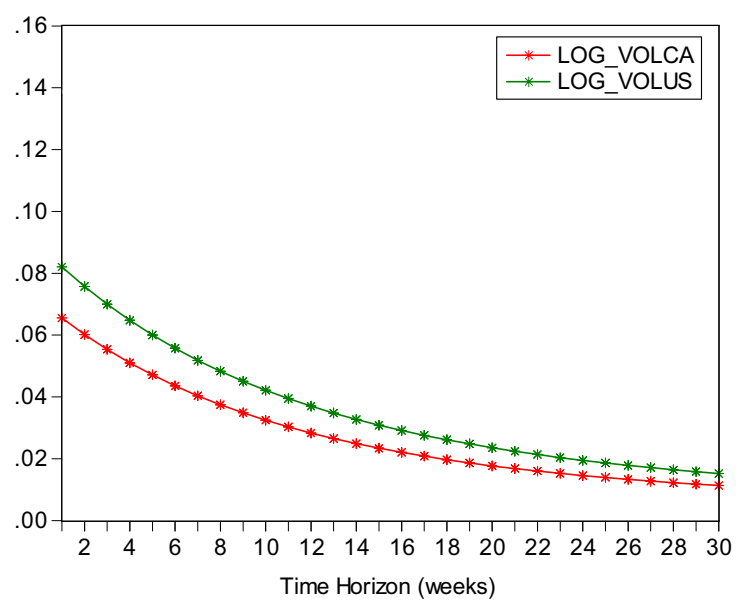

Response of Correlation between US and France Returns to Volatilities

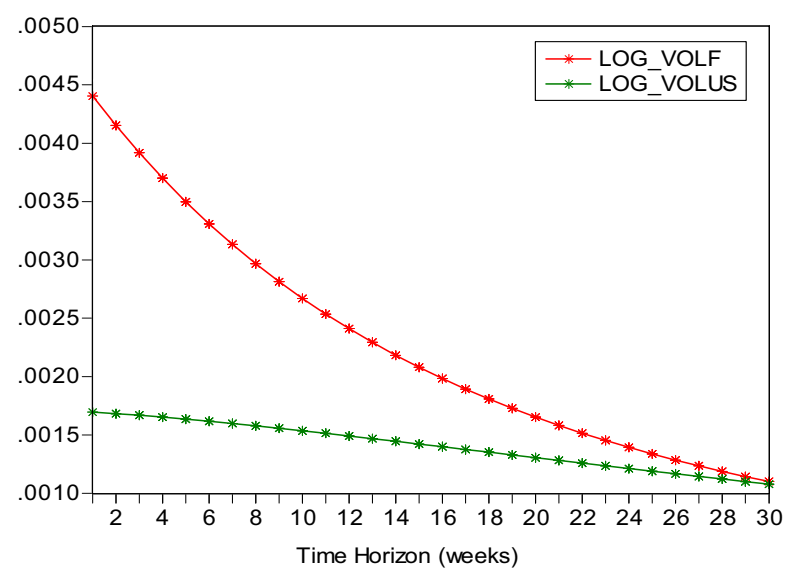

Response of Correlation between US and UK Returns to Volatilities

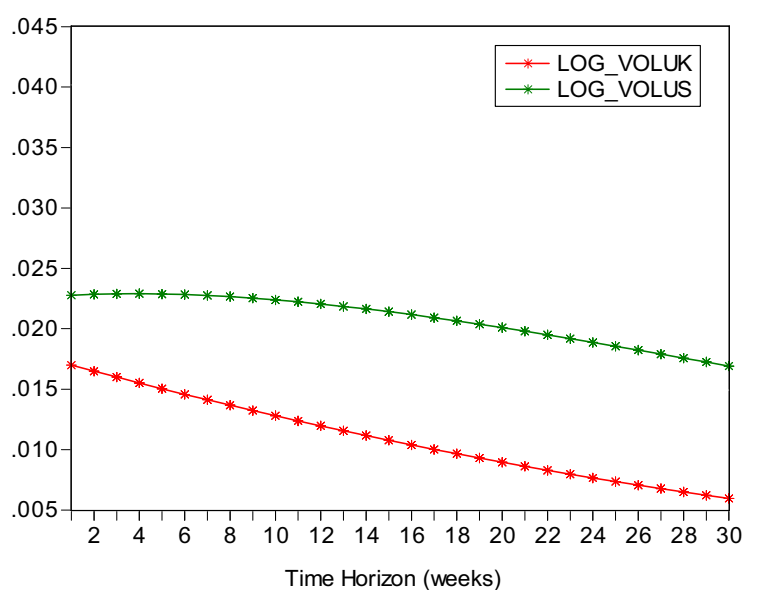

Response of Correlation between US and France Returns to Volatilities, EC model

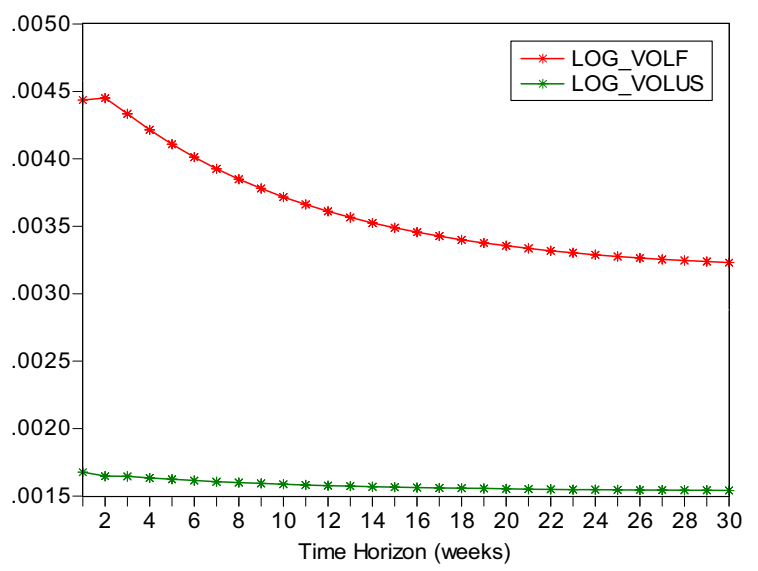

These graphs use the US, Canada, UK, and France volatilities obtained from the EGARCH $(1,1)$. The correlations US-Canada, US-UK, and US-France used for graphs are filtered from DCC model using the respective volatilities. In each graph, "LOG_VOLUS" is the curve representing the response of correlations to US volatility, while "LOG_VOLUCA" is the response of US-Canada correlation to Canada volatility, "LOG_VOLUCA" is the response of US-UK correlation to UK volatility, and "LOG_VOLUF" is the response of US-France correlation to France volatility. 
Figure 8: Impact of Nonparametric Volatilities on Correlations $(m=50)$

Response of Correlation between US and Canada Returns to Volatilities

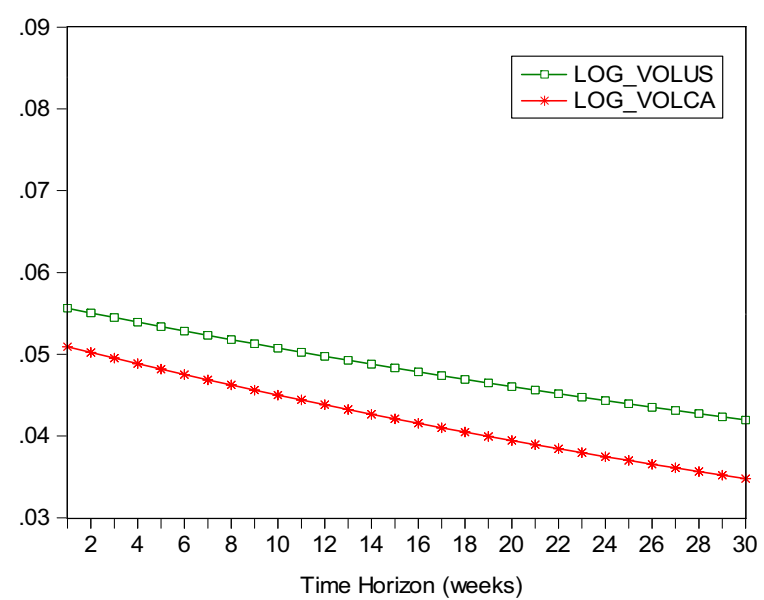

Response of Correlation between US and France Returns to Volatilities

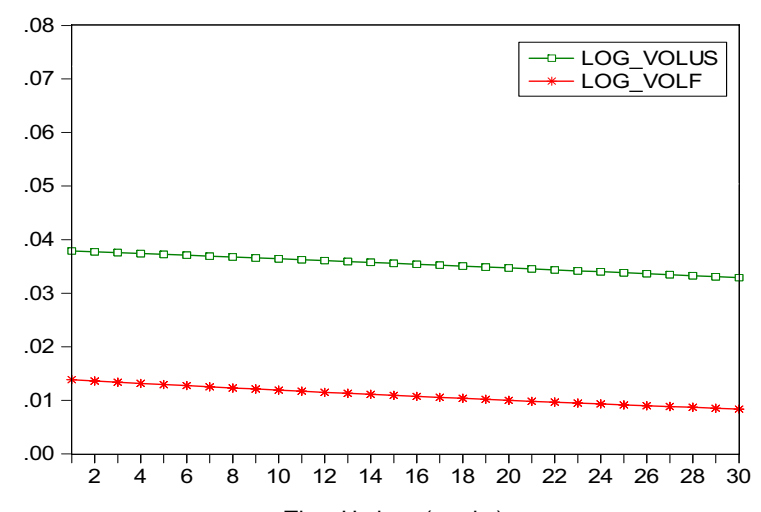

Response of Correlation between US and UK Returns to Volatilities

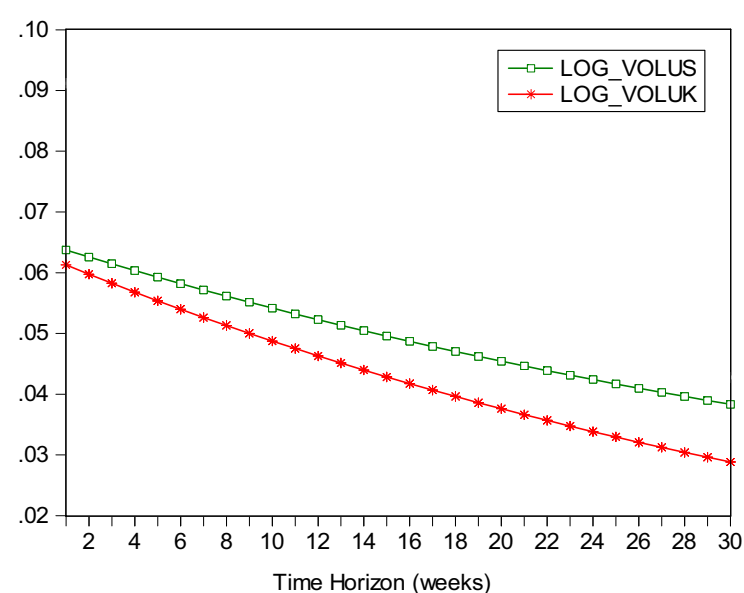

Response of Correlation between US and France Returns to Volatilities, EC model

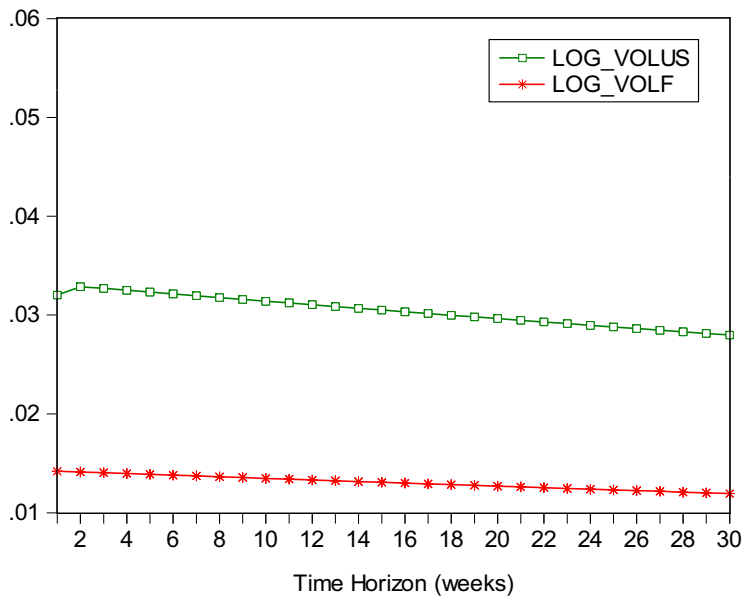

These graphs use the US, Canada, UK, and France volatilities obtained from Nonparametric estimation of volatilities (with a window of $m=50$ ). The correlations US-Canada, US-UK, and US-France used for graphs are also estimated using Nonparametric approach (with a window of $m=50)$. In each graph, "LOG VOLUS" is the curve representing the response of correlations to US volatility, while "LOG_VOLUCA" is the response of US-Canada correlation to Canada volatility, "LOG_VOLUCA" is the response of US-UK correlation to UK volatility, and "LOG_VOLUF" is the response of US-France correlation to France volatility. 
Figure 9: Impact of Nonparametric Volatilities on Correlations $(m=70)$

Response of Correlation between US and Canada Returns to Volatilities

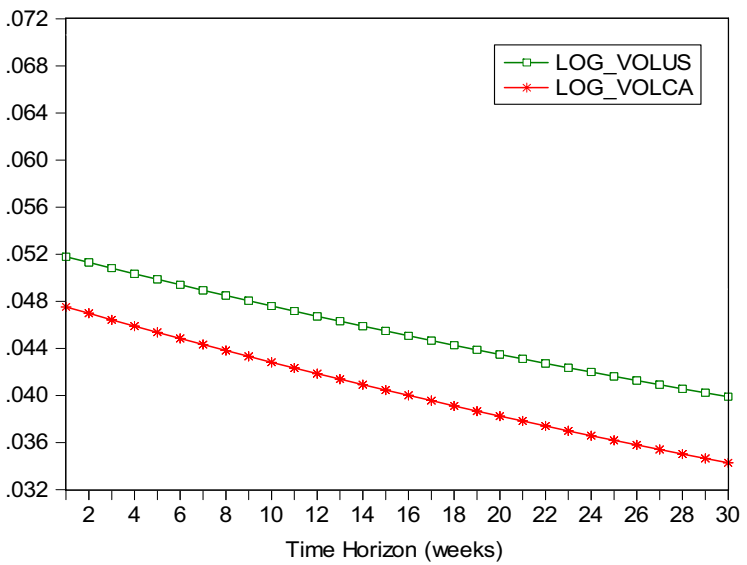

Response of Correlation between US and France Returns to Volatilities

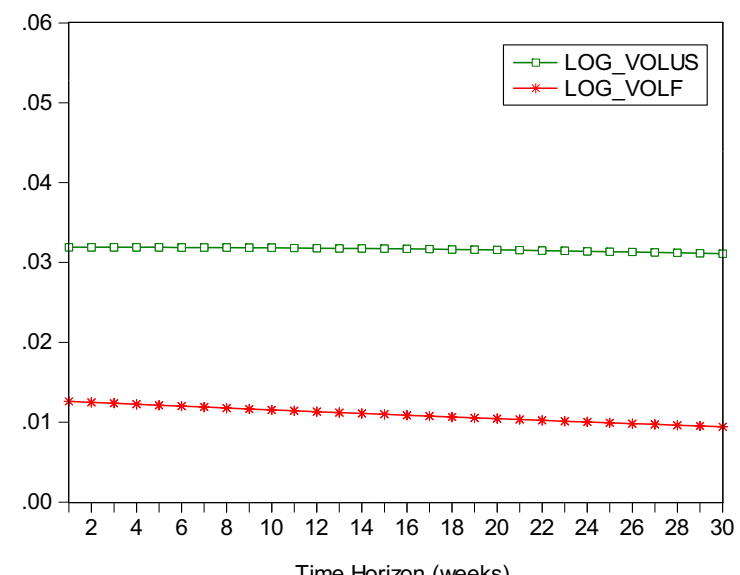

Response of Correlation between US and UK Returns to Volatilities

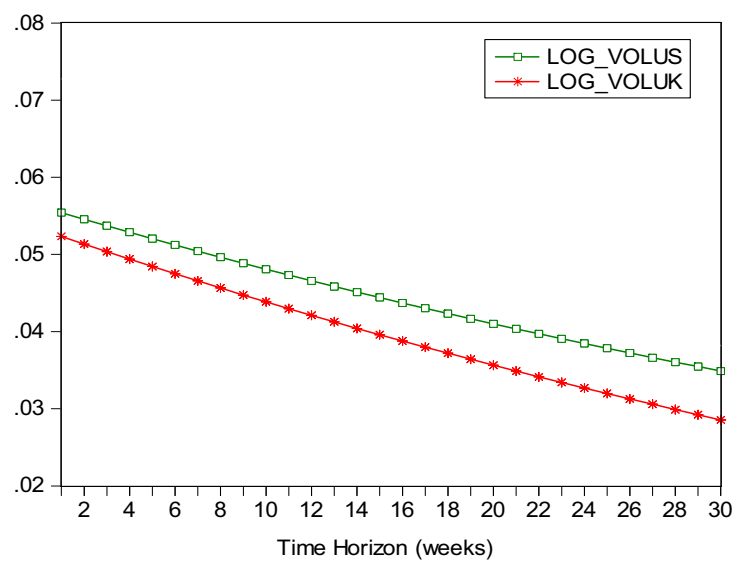

Response of Correlation between US and France Returns to Volatilities, EC model

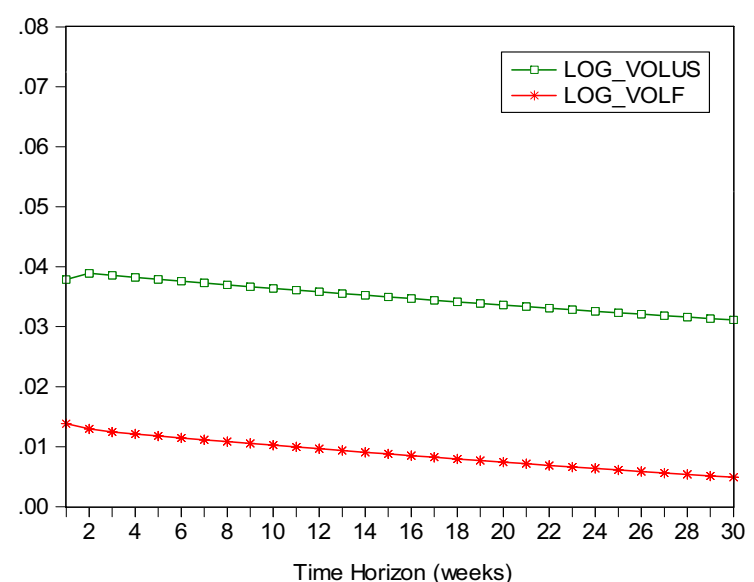

These graphs use the US, Canada, UK, and France volatilities obtained from Nonparametric estimation of volatilities (with a window of $m$ =70). The correlations US-Canada, US-UK, and US-France used for graphs are also estimated using Nonparametric approach (with a window of $m=70$ ). In each graph, "LOG_VOLUS" is the curve representing the response of correlations to US volatility, while "LOG_VOLUCA" is the response of US-Canada correlation to Canada volatility, "LOG_VOLUCA" is the response of US-UK correlation to UK volatility, and "LOG_VOLUF" is the response of US-France correlation to France volatility. 
Figure 10: Impact of Upturn and Downturn Nonparametric Volatilities on Correlations (m=50)

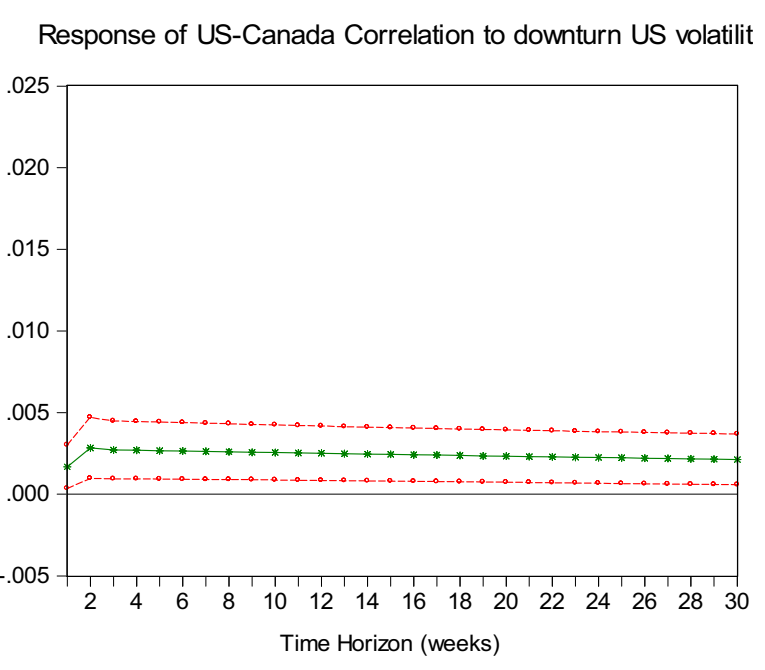

Response of US-Canada Correlation to upturn US volatility

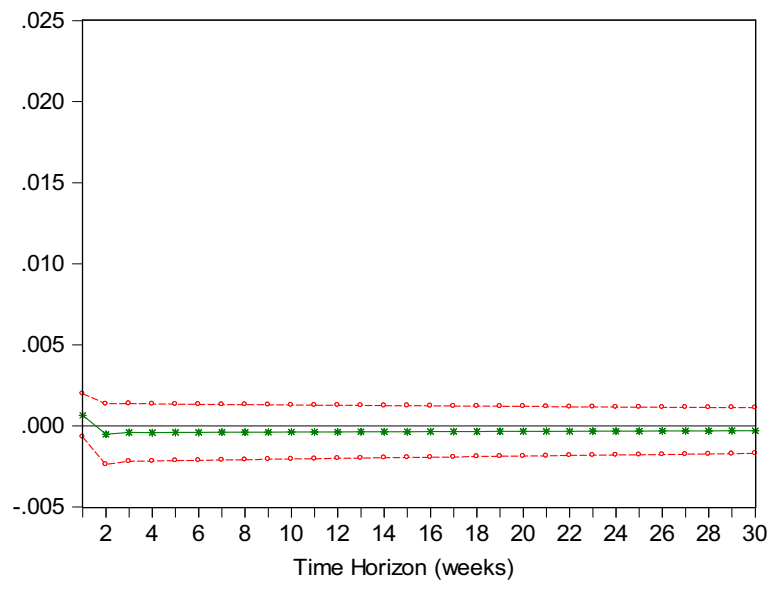

Response of US-UK Correlation to downturn US volatility

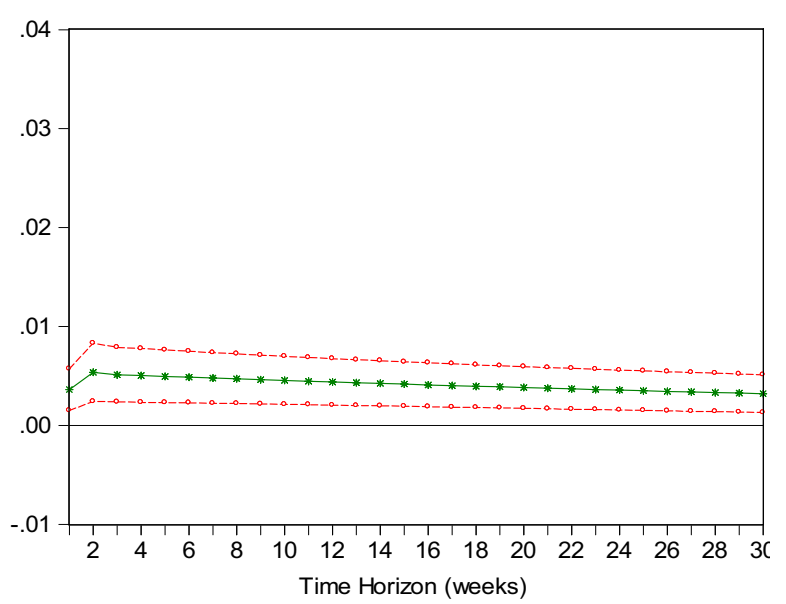

Response of US-UK Correlation to upturn US volatility

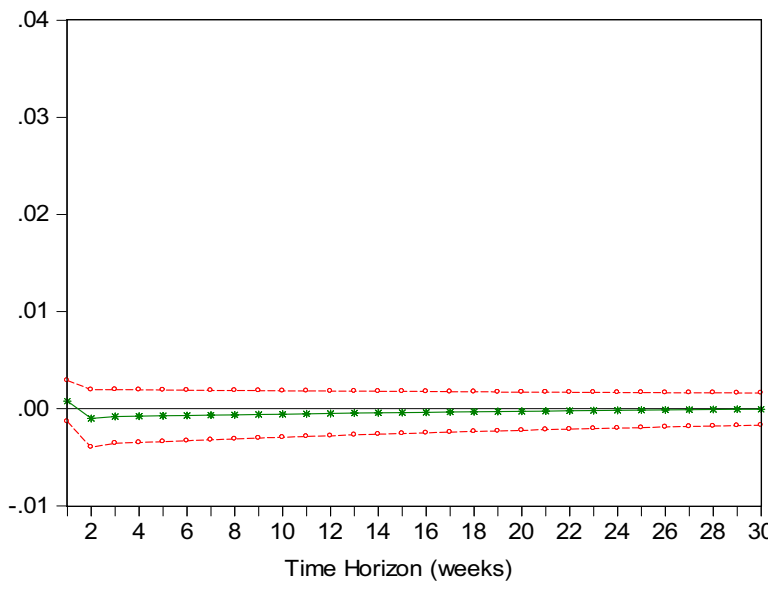

Response of US-France Correlation to downturn US volatilit

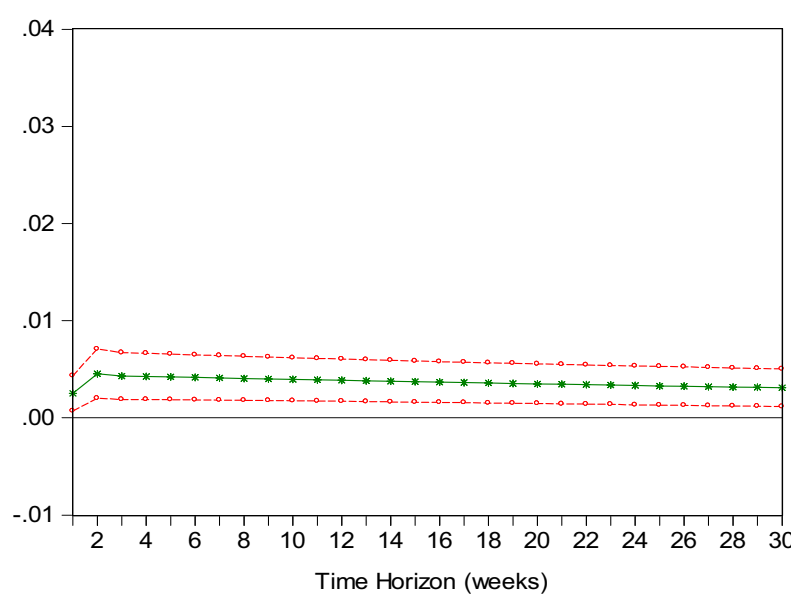

Response of US-France Correlation to upturn US volatility

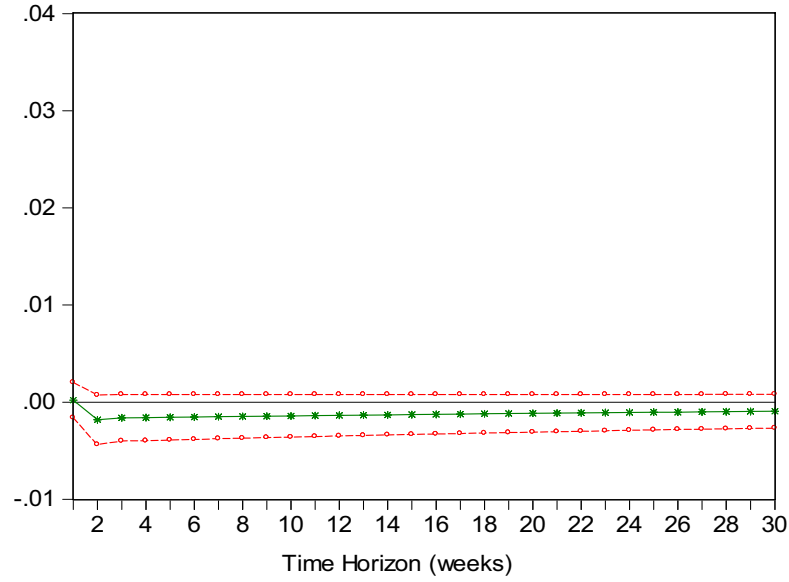

These graphs use the US, Canada, UK, and France volatilities obtained from nonparametric approach. The US-Canada, US-UK, and US-France correlations used for graphs are also estimated using nonparametric approach. All are estimates with the same window of $m=50$. For each graph, the curve in the middle represents the parameter estimates and the curves around are the $5 \%$ confidence interval for different horizons. 
Figure 11: Impact of Upturn and Downturn Nonparametric Volatilities on Correlations $(m=70)$

Response of US-Canada Correlation to downturn US volatility

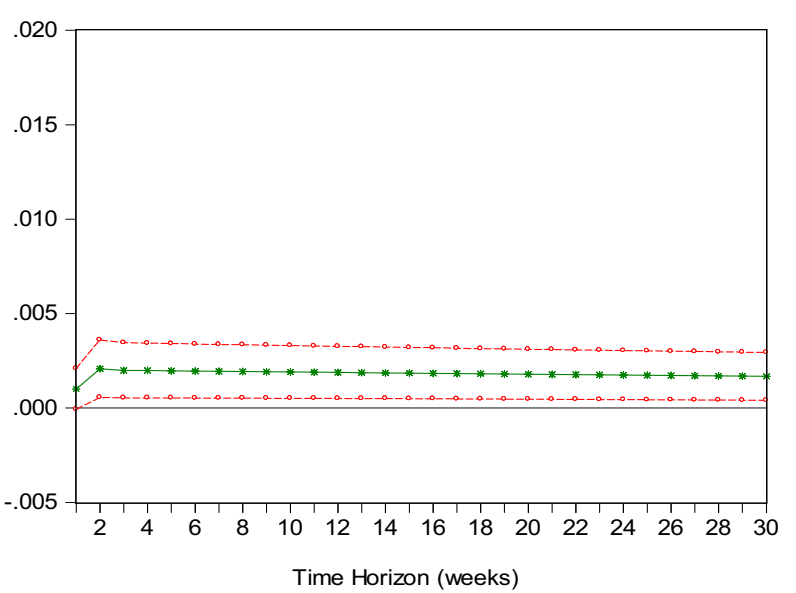

Response of US-Canada Correlation to upturn US volatility

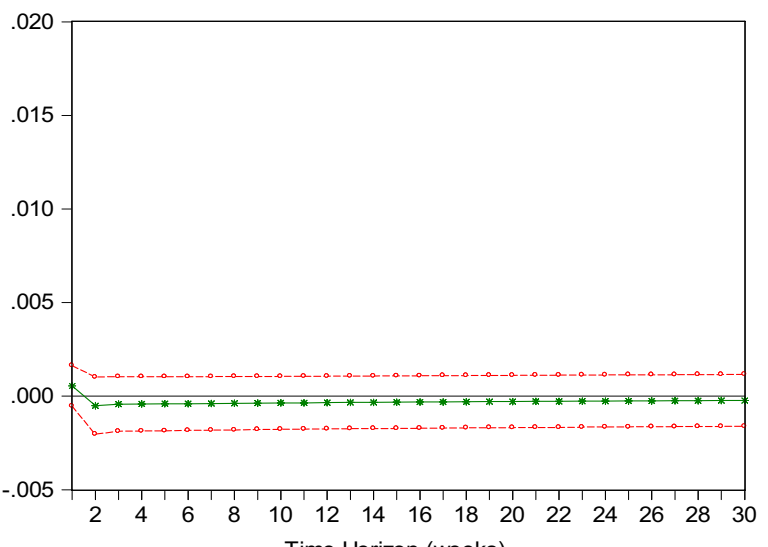

Response of US-UK Correlation to downturn US volatility

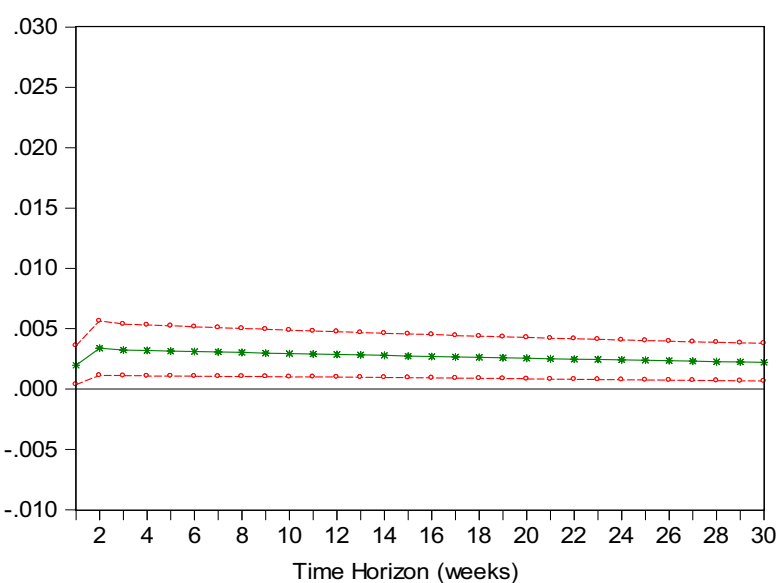

Response of US-UK Correlation to upturn US volatility

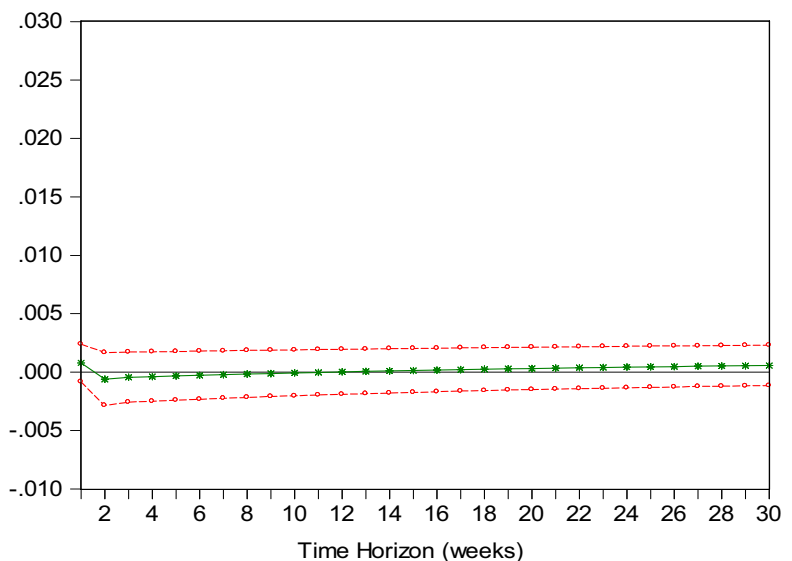

Response of US-France Correlation to downturn US volatility

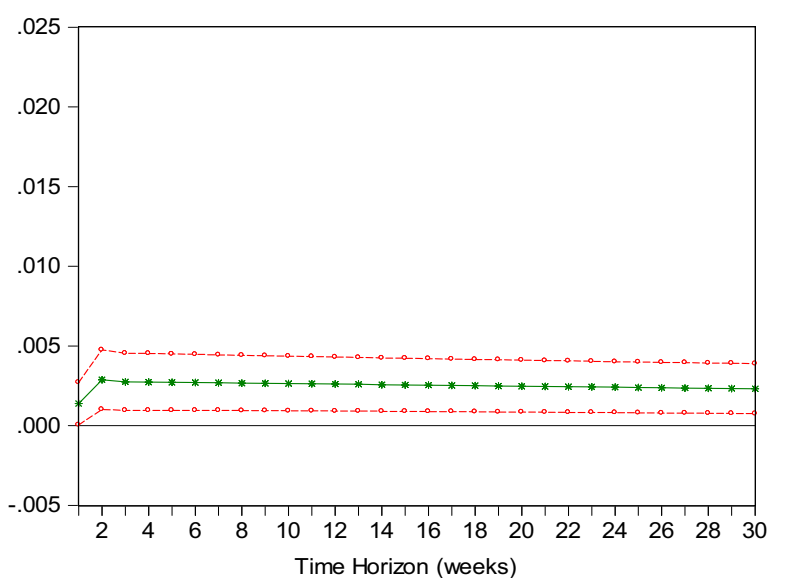

Response of US-France Correlation to upturn US volatility

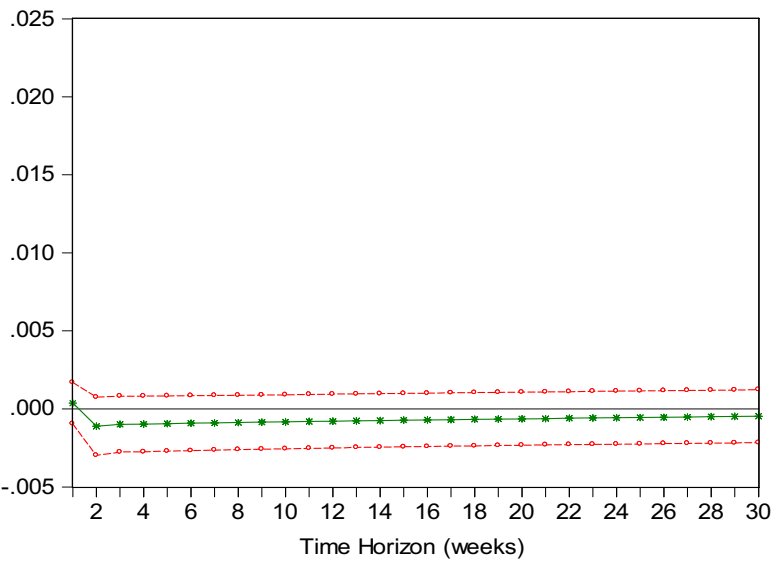

These graphs use the US, Canada, UK, and France volatilities obtained from nonparametric approach. The US-Canada, US-UK, and US-France correlations used for graphs are also estimated using nonparametric approach. All are estimates with the same window of $m=70$. For each graph, the curve in the middle represents the parameter estimates and the curves around are the $5 \%$ confidence interval for different horizons. 
Figure 12: : Impact of Bad and Good News on Correlations $(m=50)$

Response of US-Canada Correlation to Bad News

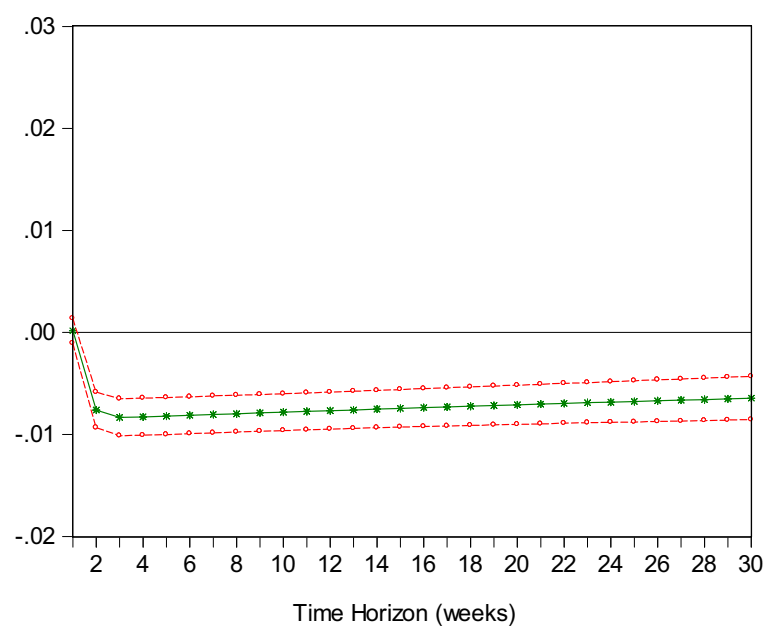

Response of US-Canada Correlation to Good News

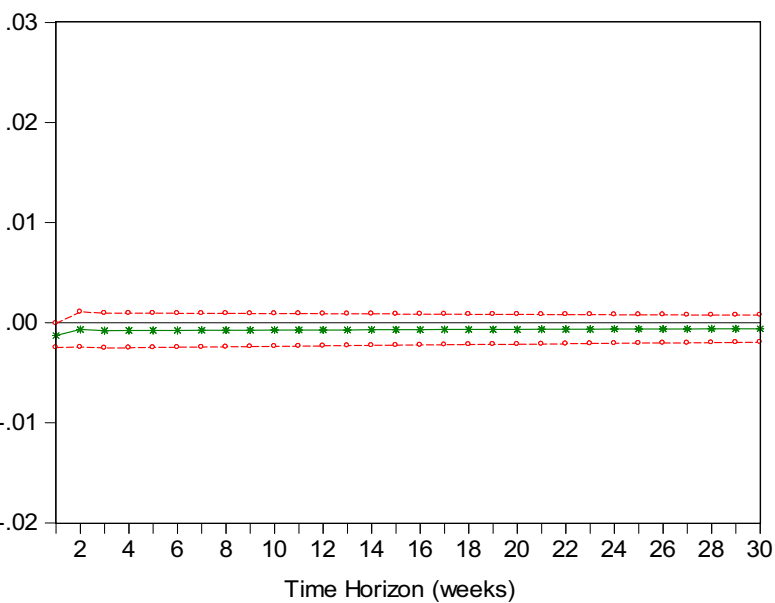

Response of US-UK Correlation to Bad News

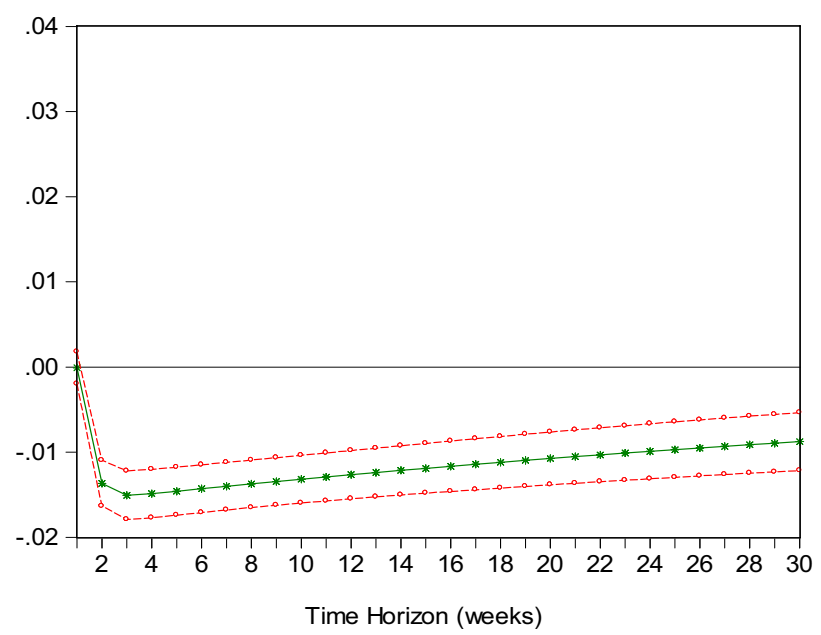

Response of US-UK Correlation to Good News

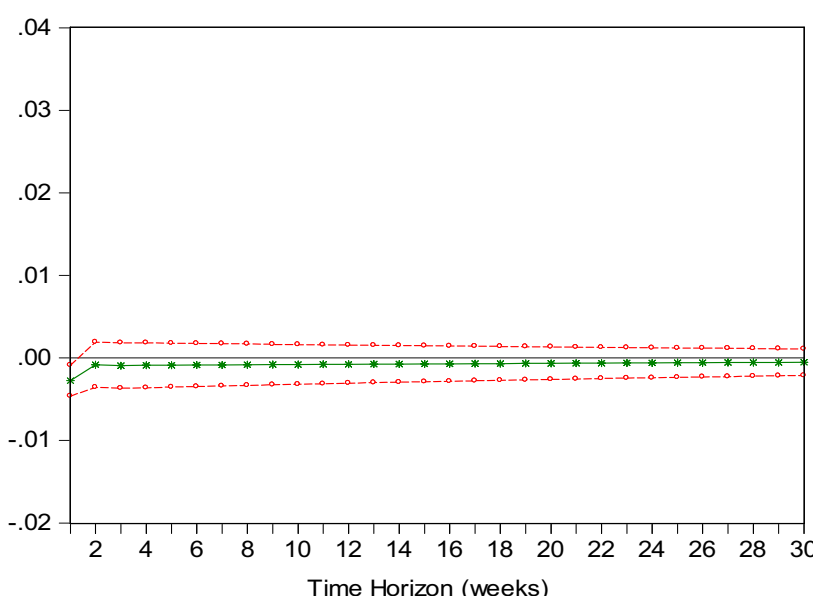

Response of US-France Correlation to Bad News

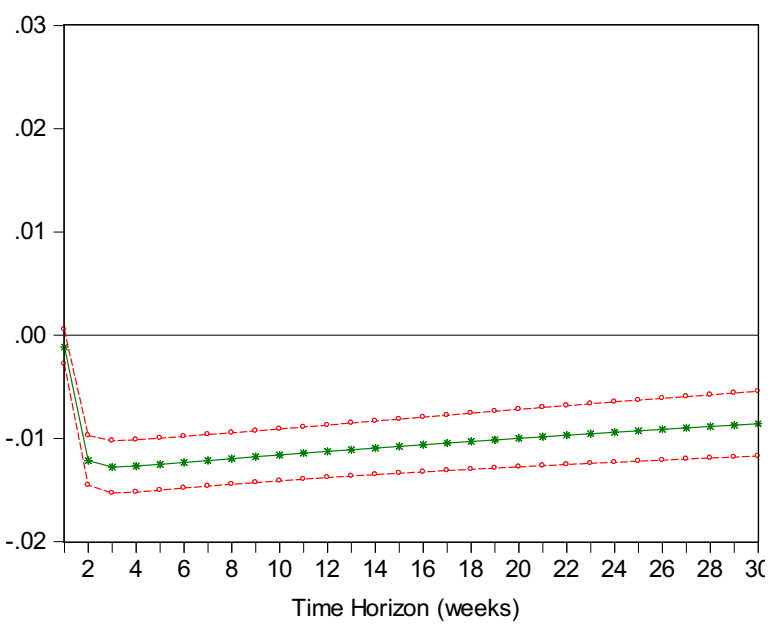

Response of US-France Correlation to Good News

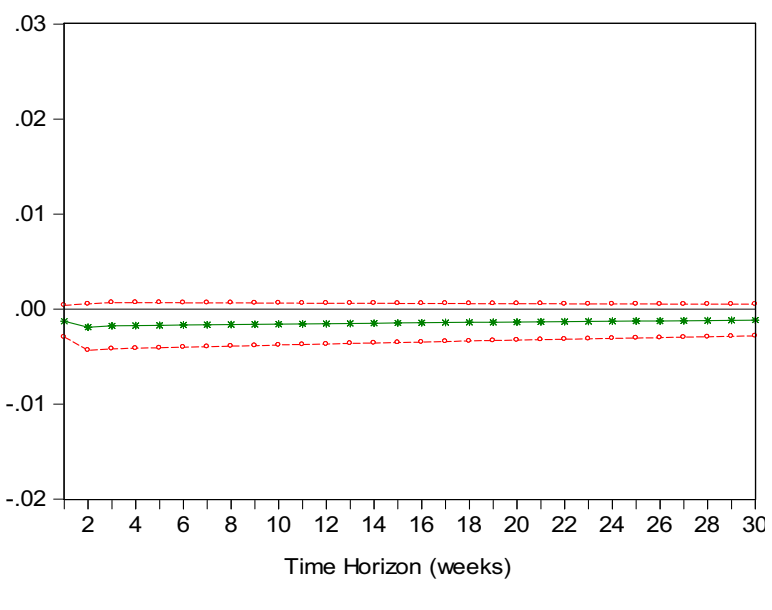

The US-Canada, US-UK, and US-France correlations used for graphs are estimated using nonparametric approach with the same window of $m=50$. For each graph, the curve in the middle represents the parameter estimates and the curves around are the 5\% confidence interval for different horizons. A negative value of the response in a bad news (negative return) means an increase in the correlation. 
Figure 13: : Impact of Bad and Good News on Correlations $(m=70)$

Response of US-Canada Correlation to Bad News

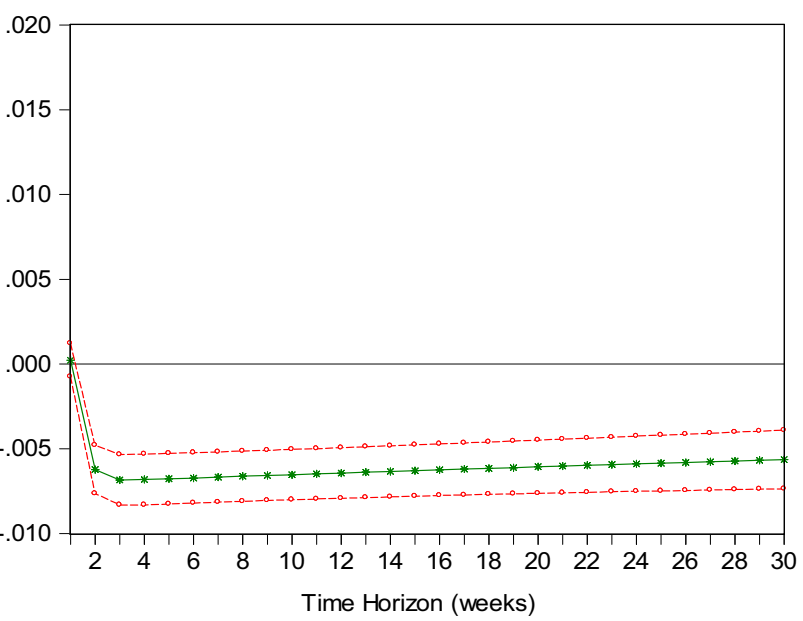

Response of US-Canada Correlation to Good News

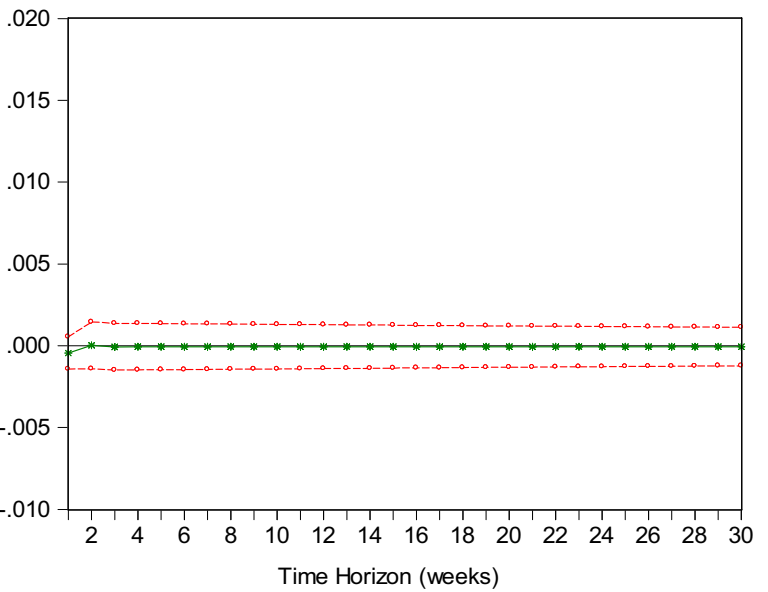

Response of US-UK Correlation to Bad News

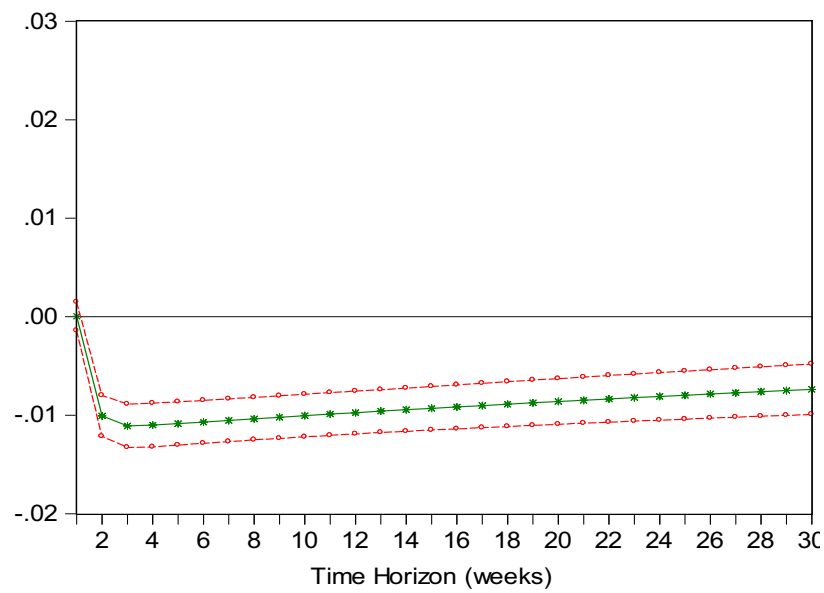

Response of US-UK Correlation to Good News

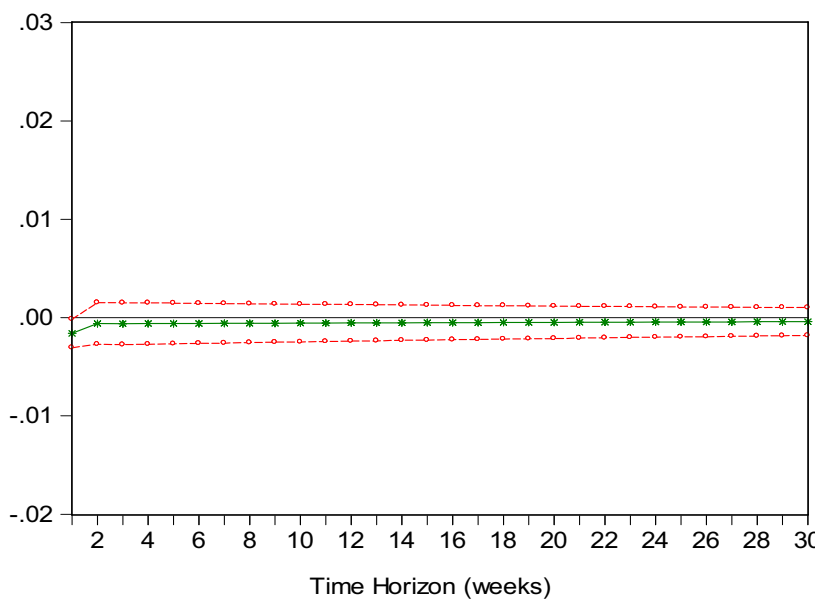

Response of US-France Correlation to Bad News

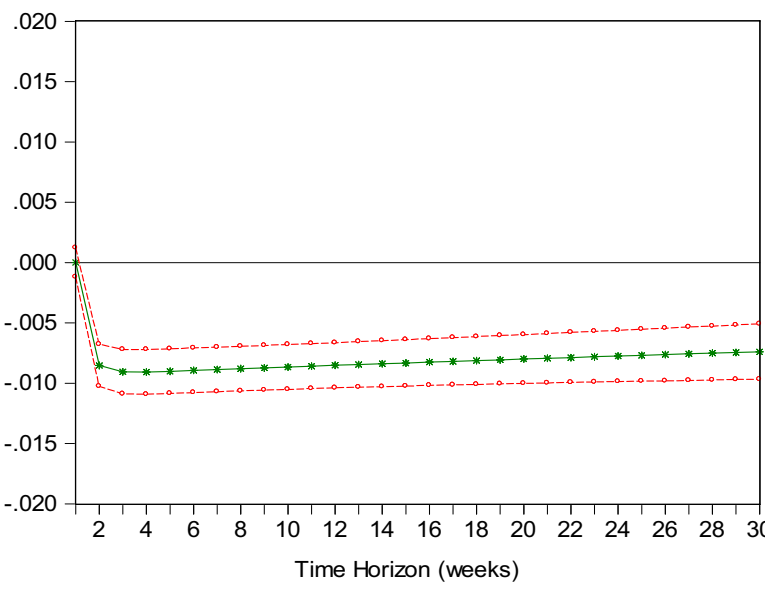

Response of US-France Correlation to Good News

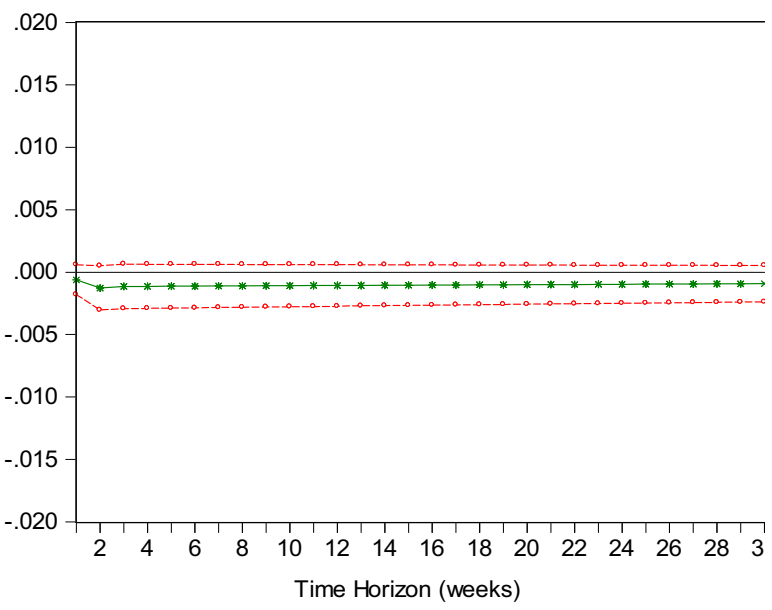

The US-Canada, US-UK, and US-France correlations used for graphs are estimated using nonparametric approach with the same window of $m=70$. For each graph, the curve in the middle represents the parameter estimates and the curves around are the $5 \%$ confidence interval for different horizons. A negative value of the response in a bad news (negative return) means an increase in the correlation. 


\section{Figure 14: Coefficients of the Asymmetries in Volatility-Correlation Relationship [With and Without Returns]}

\section{US-Canada}
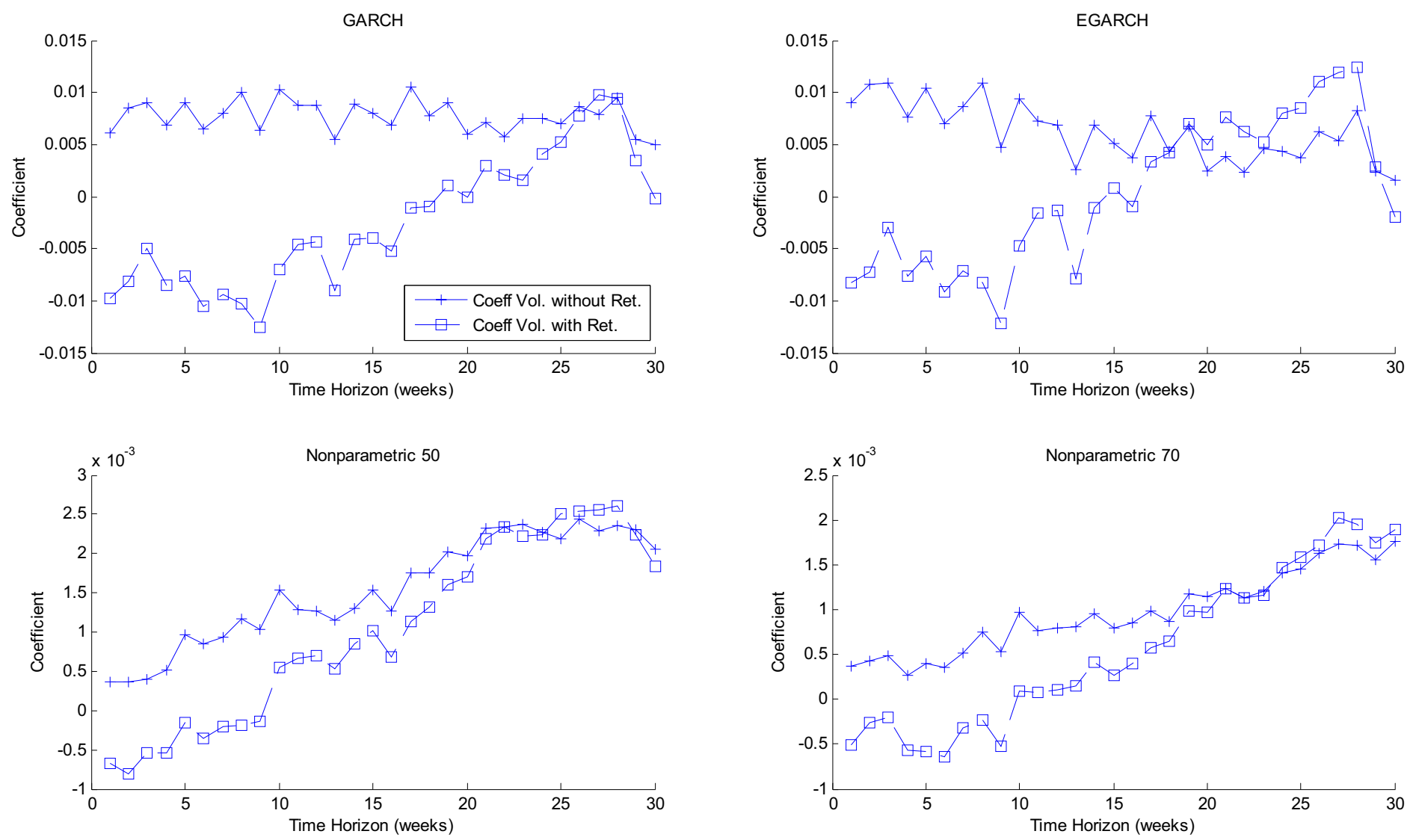

The first graph uses the US and Canada volatilities obtained from the GARCH $(1,1)$, while the second one uses the volatility filtered from EGARCH (1,1). The correlation between US and Canada used for both graphs in this first raw is filtered from DCC model using the respective volatilities. In the second raw, both graphs use nonparametric estimates (realized volatility and correlation). The third graph (Nonparametric 50), uses for estimation a window of 50 weeks, while the fourth one (Nonparametric 70 ) uses a window of 70 weeks. "Coeff Vol. Without Ret." is the curve representing the coefficient which captures the asymmetric effect of volatility on correlation in absence of returns, while "Coeff Vol. With Ret." is the coefficient which captures the same asymmetric effect when the returns effect on correlation is taken into account. 


\section{Figure 15: Coefficients of the Asymmetries in Volatility-Correlation Relationship [With and Without Returns]}

\section{US-UK}
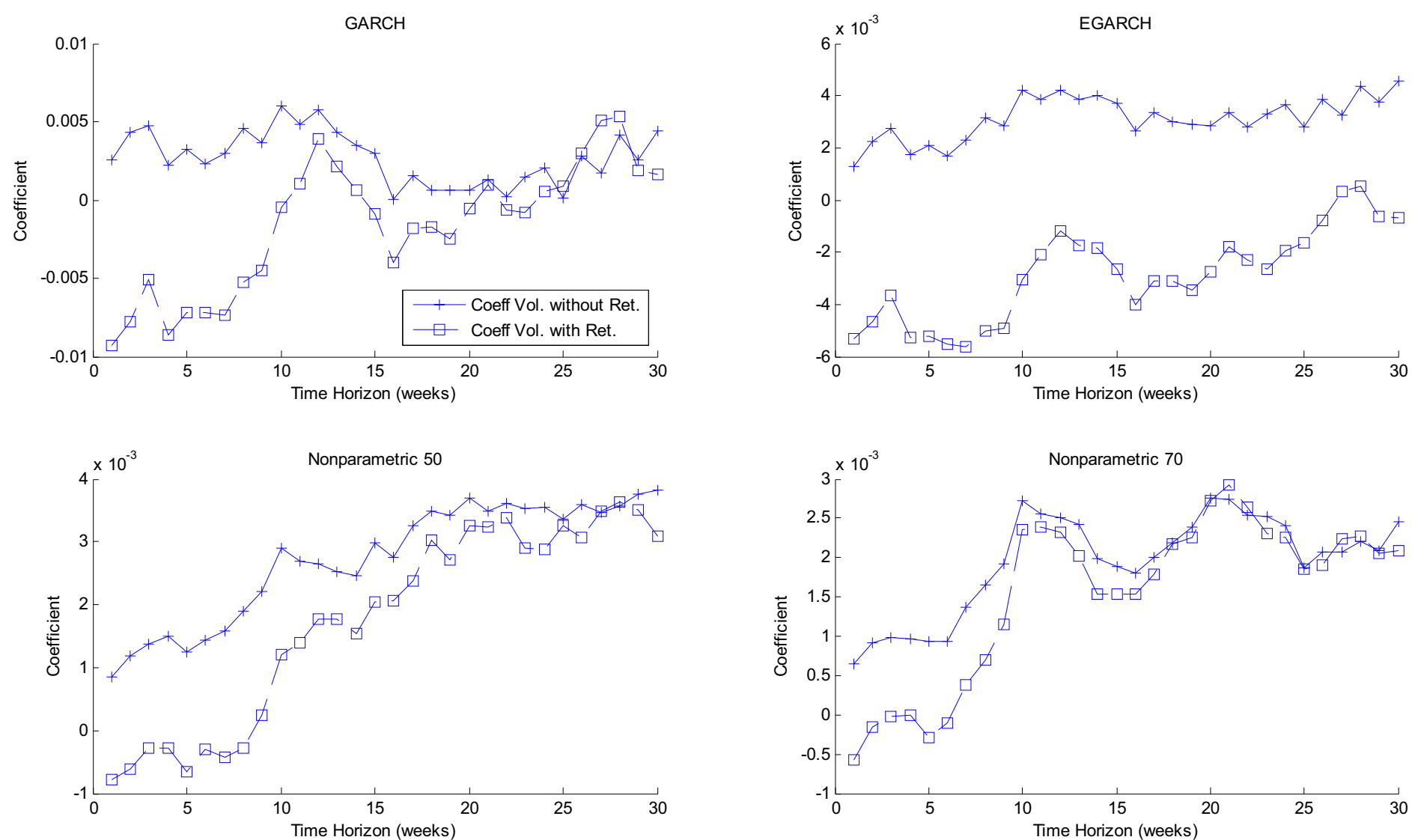

The first graph uses the US and UK volatilities obtained from the GARCH $(1,1)$, while the second one uses the volatility filtered from EGARCH $(1,1)$. The correlation between US and UK used for both graphs in this first raw is filtered from DCC model using the respective volatilities. In the second raw, both graphs use nonparametric estimates (realized volatility and correlation). The third graph (Nonparametric 50), uses for estimation a window of 50 weeks, while the fourth one (Nonparametric 70) uses a window of 70 weeks. "Coeff Vol. Without Ret." is the curve representing the coefficient which captures the asymmetric effect of volatility on correlation in absence of returns, while "Coeff Vol. With Ret." is the coefficient which captures the same asymmetric effect when the returns effect on correlation is taken into account. 


\section{Figure 16: Coefficients of the Asymmetries in Volatility-Correlation Relationship [With and Without Returns]}

\section{US-France}
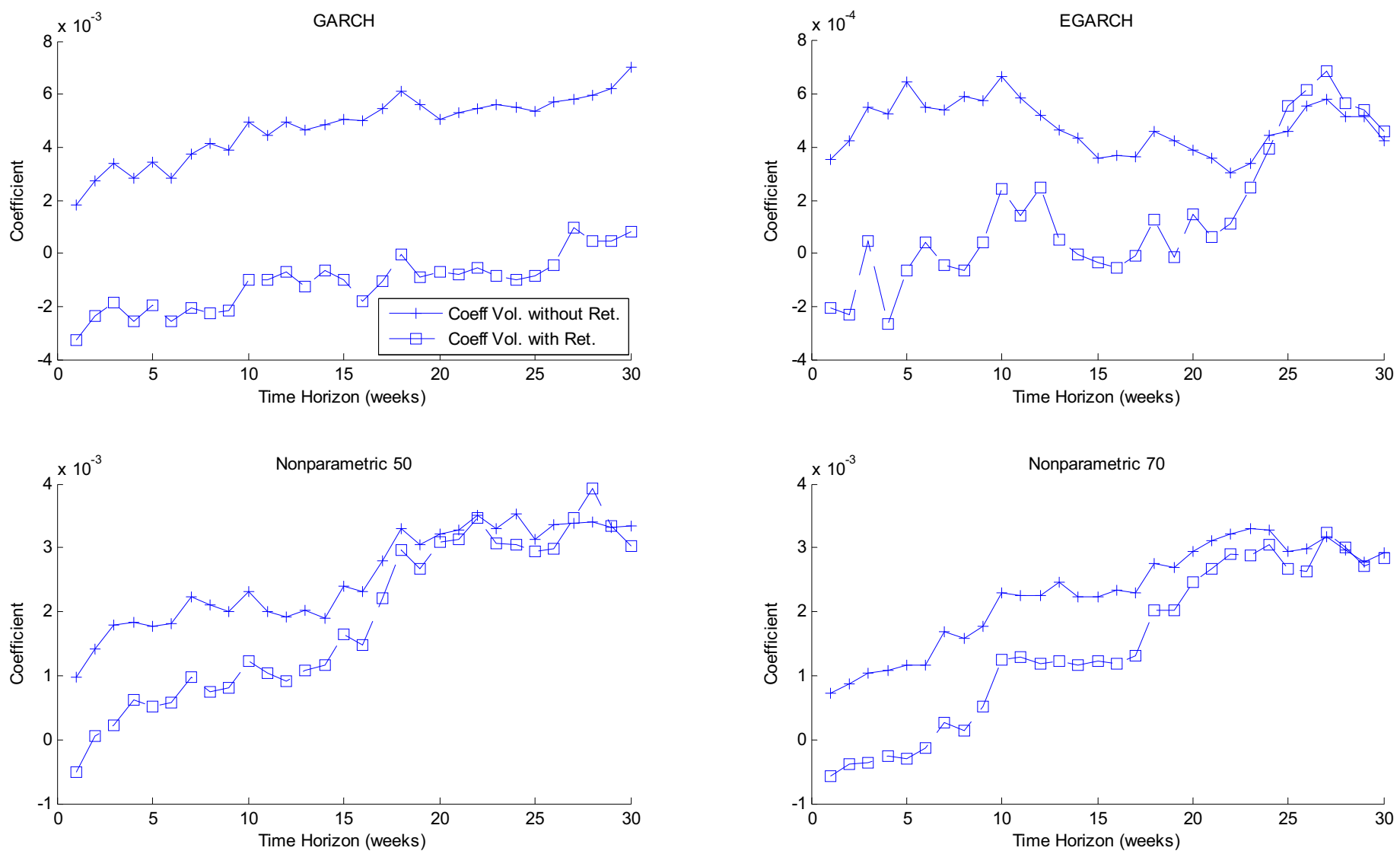

The first graph uses the US and France volatilities obtained from the GARCH $(1,1)$, while the second one uses the volatility filtered from EGARCH $(1,1)$. The correlation between US and France used for both graphs in this first raw is filtered from DCC model using the respective volatilities. In the second raw, both graphs use nonparametric estimates (realized volatility and correlation). The third graph (Nonparametric 50), uses for estimation a window of 50 weeks, while the fourth one (Nonparametric 70) uses a window of 70 weeks. "Coeff Vol. Without Ret." is the curve representing the coefficient which captures the asymmetric effect of volatility on correlation in absence of returns, while "Coeff Vol. With Ret." is the coefficient which captures the same asymmetric effect when the returns effect on correlation is taken into account. 
Figure 17: Tests of the Asymmetries in Volatility-Correlation and Returns-Correlation Relationships

\section{US-Canada}
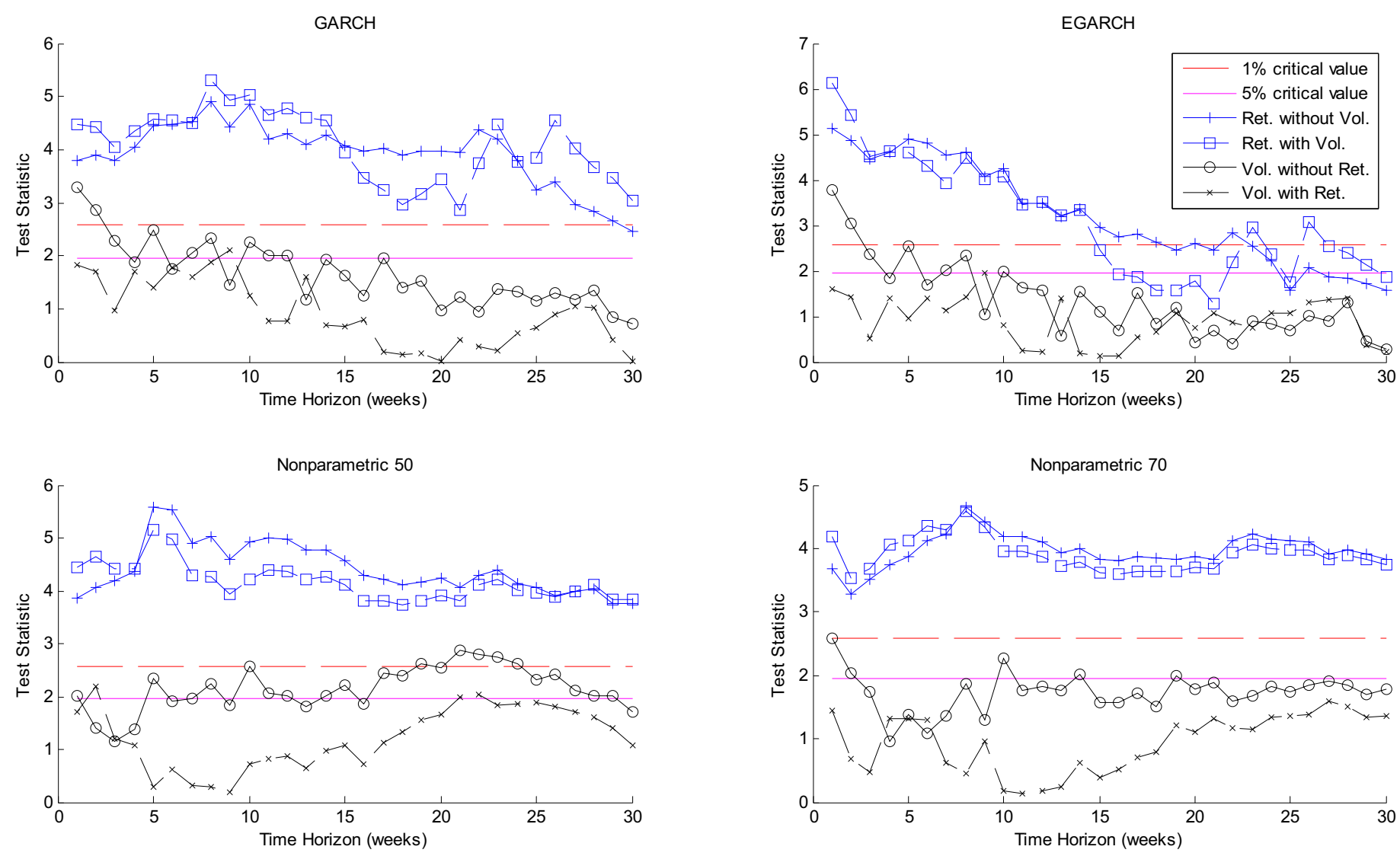

The first graph uses the US and Canada volatilities obtained from the GARCH $(1,1)$, while the second one uses the volatility filtered from EGARCH (1,1). The correlation between US and Canada used for both graphs in this first raw is filtered from DCC model using the respective volatilities. In the second raw, both graphs use nonparametric estimates (realized volatility and correlation). The third graph (Nonparametric 50), uses for estimation a window of 50 weeks, while the fourth one (Nonparametric 70 ) uses a window of 70 weeks. "Ret. Without Vol." is the curve representing the test statistic for the asymmetric effect of return on correlation in absence of volatility, while "Ret. With Vol." is the same test statistic when the volatility effect on correlation is taken into account. Similarly, "Vol. Without Ret." is the test statistic for the asymmetric effect of volatility on correlation in absence of return, while "Vol. With Ret." represents this test statistic when the effect of return on correlation is taken into account. 


\section{Figure 18: Tests of the Asymmetries in Volatility-Correlation and Returns-Correlation Relationships}

\section{US-UK}
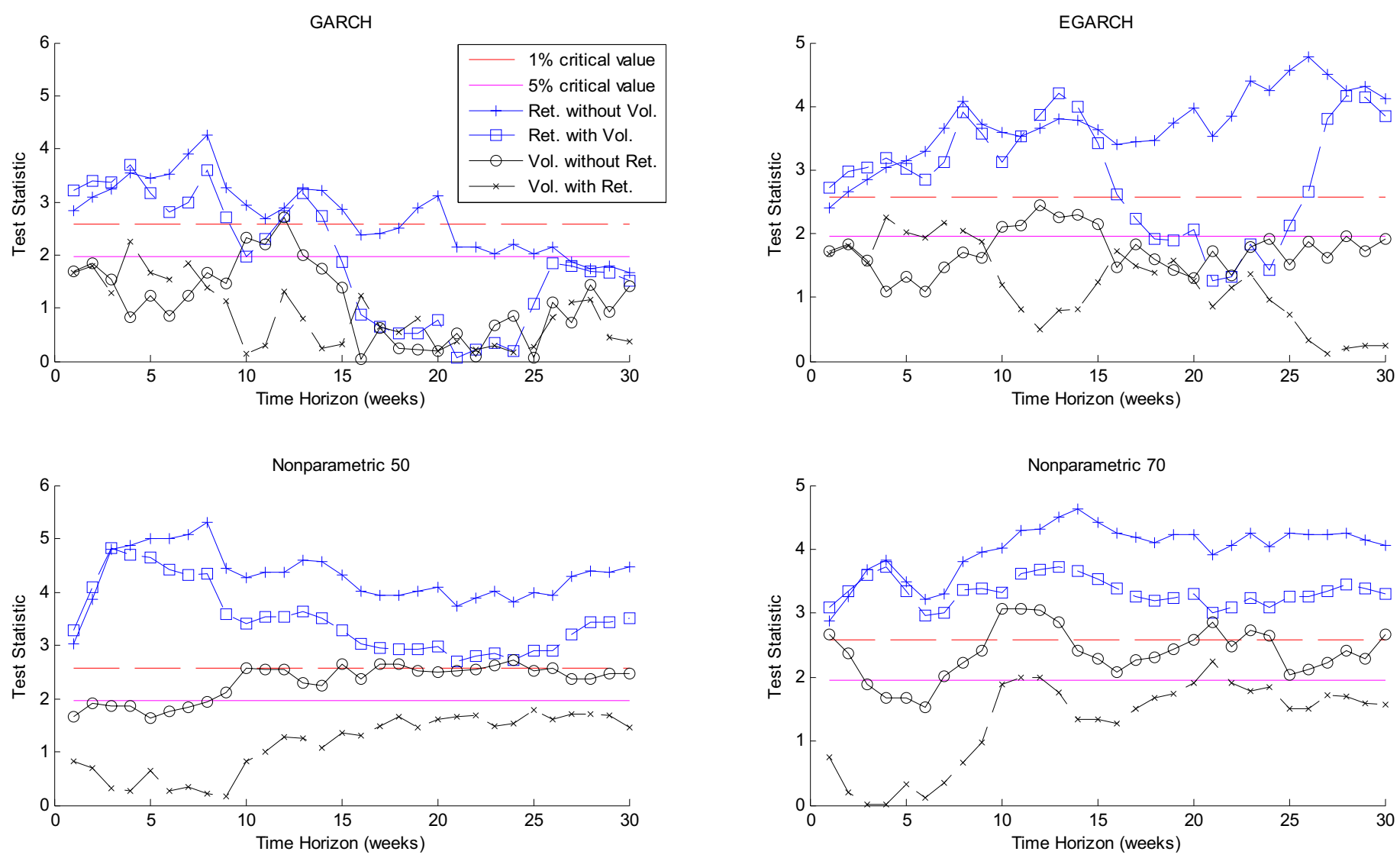

The first graph uses the US and UK volatilities obtained from the GARCH $(1,1)$, while the second one uses the volatility filtered from EGARCH $(1,1)$. The correlation between US and UK used for both graphs in this first raw is filtered from DCC model using the respective volatilities. In the second raw, both graphs use nonparametric estimates (realized volatility and correlation). The third graph (Nonparametric 50 ), uses for estimation a window of 50 weeks, while the fourth one (Nonparametric 70) uses a window of 70 weeks. "Ret. Without Vol." is the curve representing the test statistic for the asymmetric effect of return on correlation in absence of volatility, while "Ret. With Vol." is the same test statistic when the volatility effect on correlation is taken into account. Similarly, "Vol. Without Ret." is the test statistic for the asymmetric effect of volatility on correlation in absence of return, while "Vol. With Ret." represents this test statistic when the effect of return on correlation is taken into account. 


\section{Figure 19: Tests of the Asymmetries in Volatility-Correlation and Returns-Correlation Relationships}

\section{US-France}
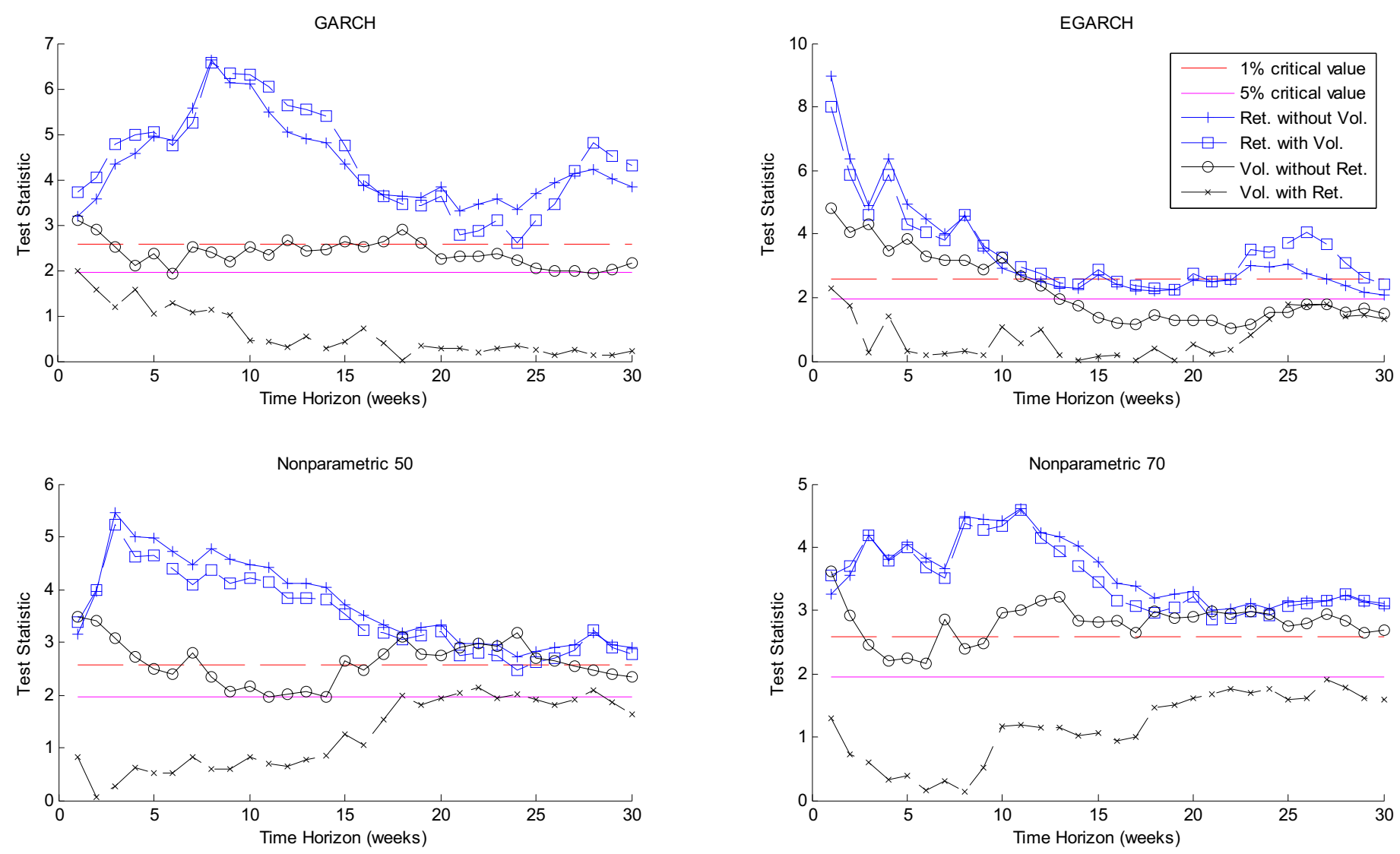

The first graph uses the US and France volatilities obtained from the GARCH (1,1), while the second one uses the volatility filtered from EGARCH (1,1). The correlation between US and France used for both graphs in this first raw is filtered from DCC model using the respective volatilities. In the second raw, both graphs use nonparametric estimates (realized volatility and correlation). The third graph (Nonparametric 50), uses for estimation a window of 50 weeks, while the fourth one (Nonparametric 70 ) uses a window of 70 weeks. "Ret. Without Vol." is the curve representing the test statistic for the asymmetric effect of return on correlation in absence of volatility, while "Ret. With Vol." is the same test statistic when the volatility effect on correlation is taken into account. Similarly, "Vol. Without Ret." is the test statistic for the asymmetric effect of volatility on correlation in absence of return, while "Vol. With Ret." represents this test statistic when the effect of return on correlation is taken into account. 